\title{
Women's perceptions of health, quality of life, and malaria management in Kakamega County, Western Province, Kenya
}

\author{
Florence V. Dunkel • Leanna M. Hansen • \\ Sarah J. Halvorson · Arthur Bangert
}

Published online: 4 May 2016

(C) The Author(s) 2016. This article is published with open access at Springerlink.com

\begin{abstract}
We assess women's perceptions of health risks in relation to quality of life concerns, with attention to variables viewed as central to maintaining or improving health and well-being. In this paper, we specifically underscore how a life-threatening disease-malaria-is experienced and bio-cyclically understood and managed in relation to seasonal hunger, food insecurities, and livelihood vulnerabilities. The study, conducted June-July 2013, draws on field data and interviews with 60 women farmers of the Luhya community along the Yala River in Kakamega County, Western Province, Kenya. Major findings suggest the following: (1) women's perceived desired quality of life is shaped by priorities for children's education, nutrition, food security, and economic security in their rural communities; (2) malaria
\end{abstract}

F. V. Dunkel $(\varangle)$

Department of Plant Sciences and Plant Pathology, Montana State University, Bozeman, MT 59717, USA e-mail: fdunkel@montana.edu

\section{M. Hansen}

Department of Cell Biology and Neuroscience, Montana State University, Bozeman, MT 59717, USA

\section{S. J. Halvorson}

Department of Geography, University of Montana, Missoula, MT 59812, USA

\author{
A. Bangert \\ Department of Education, Montana State University, \\ Bozeman, MT 59717, USA
}

emerged as a challenging household health problem that curtails livelihood opportunities for most study participants; and (3) local understandings of malaria transmission, particularly how and when female mosquitoes become infected with malaria-causing protozoans, was low, but malaria symptoms were relatively well-understood. The interest and motivation to institute new malaria risk reduction practices at the community level are explored, including attention to building upon the Luhya tradition of oral storytelling in order to promote actions to eliminate malaria. This analysis of local narratives of health risks illustrates these points and demonstrates how women's constructions of health risks and well-being provide a basis for developing interventions targeting income generation and microloan opportunities that could support Kenyan women in their intersecting approaches to malaria, securing nutritious diets, and enhancing the local health environment.

Keywords Malaria Anopheles gambiae - Women farmers · Perceptions · Health education - Biocycle storytelling $\cdot$ Holistic process

\section{Introduction}

This article examines how women's perceptions of health and well-being in Kakamega County, Western Province, Kenya speak to complex socio-ecological 
circumstances that influence malaria management and other perceived and observed health risks. In this part of Kenya malaria is a significant public health concern-both the two chronic recurring forms and the cerebral acute form-are normalized, accepted and absorbed as part of life and livelihood for families facing severe poverty. The Kenyan Ministry of Health recently reported that in just 1 year there were 232,383 clinical cases of malaria in children under age five, of which 64,127 cases of malaria were confirmed with blood tests (KNBS 2012). The cerebral, acute form of malaria is less common, accounting for approximately $3 \%$ of the deaths of children under 5 years of age (MCH/WHO 2014). Recent health surveys confirm that Kakamega County has Kenya's highest annual transmission rate of malaria coupled with some of the highest incidence of kwashiorkor and other forms of severe under-nutrition ${ }^{1}$ (KNBS 2009, 2012; Thurow 2012). Further complicating the child health picture in Kakamega County are pneumonia and diarrhea, two other leading causes of global child mortality (WHO 2014a).

Over 3.3 billion people in 106 countries live in zones at risk to malaria, with $91 \%$ of reported malaria cases occurring in Kenya and other places in SubSaharan Africa (CDC 2015; WHO 2014b). A startling statistic is that despite the Millennium Development Goals and Africa-focused malaria eradication campaigns, approximately 627,000 deaths of mainly SubSaharan African children are still attributed to malaria each year (WHO 2014c). Billions of dollars have been spent on research to eliminate and cure the disease, but only recently in 2015 has the first effective vaccine to combat malaria been approved (Omole et al. 2015). It is worth noting, however, that investment and

\footnotetext{
1 Under-nutrition contributes to more than one-third of all deaths of Kenyan children under 5 (WHO 2014a). Undernutrition occurs in the form of kwashiorkor (protein energy malnutrition $[\mathrm{PEM}]$ ) and other micronutrient deficiencies and as well as in the form of marasmus which is total lack of calories. The dominant corn-based diet in Kakamega County is missing two essential amino acids because these are not present in corn. Although beans, Phaseolus vulgaris, were introduced with corn to East Africa, beans became the main source of protein and calories in what is now Rwanda, Burundi, and Uganda rather than in Kenya. Food insects common throughout sub-Saharan Africa, including in Kenya, can supply the essential amino acids missing in corn, and are more nutrient dense than corn. Western cultures have influenced an abandonment of this nutritious traditional snack (van Huis et al. 2013; Looy et al. 2013).
}

innovations in malaria control have resulted in an overall decrease in malaria-related mortality, with an estimated $40 \%$ reduction in children's deaths from malaria since 2000 (UNICEF 2013; WHO 2014b, c). Evidence and past experience suggest that where significant decreases in funding for malaria interventions have occurred, eradication methods ultimately wane as well, with the result being a "Sisyphean challenge" of never fully seeing the incidence of malaria curtailed in these particular places (Smith et al. 2011). Clearly, the uncertainties surrounding funding makes it fully evident that populations at risk need access to locally-informed sustainable tools and information, including bio-cycle storytelling ${ }^{2}$ to control and reduce the levels of malaria incidence (Dunkel et al. 2013).

Kenya is classified as a country controlling malaria rather than one that is actively trying to eliminate the disease (Feachem 2009). The intensity of malaria transmission and frequency of malaria importation is

2 Bio-cycle storytelling is a term coined by Dunkel et al. (2013)
to use storytelling, which is part of the oral tradition of Africans,
to convey complex biological, ecological or evolutionary shifts.
In this research site, bio-cycle storytelling was aimed at teaching
the evolutionary shifts in mosquito behavior. This form of
conveying information uses a narrative to describe the life
cycles in story form of the two organisms whose life cycles
intertwine to pass malaria between humans. In the story
narrative these two groups of organisms, the species of
anopheline mosquitoes and the species of protists that cause
malaria take the form of human characters with various
motivations including survival and procreation and who use
deception and careful knowledge of humans' typical behavior
patterns. In these Malian communities where bio-cycle storytelling was developed by Dunkel et al., stagnant water disappeared, larvae were monitored, and villagers readily learned to use neem leaves, Azadirachta indica from local trees to create an insect growth regulator safe to use in semi-permanent stagnant water (Luong et al. 2012). When significantly less malaria was locally observed and documented, villagers conveyed the bio-cycle stories to nearby villages in part to help other communities facing high rates of malaria and in part to prevent the reintroduction of the malaria protozoan back into their own community. Thus, a self-perpetuating horizontal diffusion of malaria-related knowledge resulted. This informal story telling process was based on methods used in remote villages in southern Mali where cerebral malaria was considered the main impediment to villagers attaining their desired quality of life (Dunkel et al. 2013). This work in Mali suggests that when information is by the community and for the community, actions supporting malaria management and eradication will be adjusted through community creativity to the local geography, environmental concerns, and seasonality. 
high, in part, because Kenya is bordered by countries that are also only controlling malaria rather than working towards eradication (Feachem 2009). Community involvement is viewed as central to sustainable malaria reduction and eventual elimination in the Kenyan National Malaria Control Strategy. Local socioeconomic support could prove highly effective in long term malaria prevention (Tusting et al. 2013) (Table 1). Links between lifestyle, such as living near a fish pond or rice production area, and infection with the human malaria Plasmodium is understood (Matthys et al. 2006). Equally important is understanding the knowledge, perceptions, practices, and healthseeking behavior of people at-risk for malaria (Abubakar et al. 2013; Doannio et al. 2004).

Studies have shown how attention to individual agency and collective action can improve health conditions and disease patterns even in the face of macro-level economic and socio-political structures and environmental factors that can constrain local actions (Bisung et al. 2015; Dunkel et al. 2013). One critical place for intervention we see is to investigate understandings and perceptions of malaria within the broader context of geographical situations, socioeconomic processes, and environmental changes that shape inequalities of exposure and survivorship in one of Sub-Saharan Africa's most malaria-prone areas. Building upon the literature, this paper examines malaria, health risks and quality-of-life in a rural agricultural community situated along the Yala River. The goal of the study was to begin to systematically unravel the factors contributing to a story of poor health in this particular place.

Starting with the perceptions of women, the purpose of this article is three-fold: one, to reveal the scope of experiences with and interpretations of malaria and concomitant health risks; two, to understand how social and environmental factors and changes and agricultural change influence these experiences and interpretations of malaria-related impacts and other health realities; and three, to identify what malaria management information and communication strategies would help to prevent malaria transmission. Overall, we sought to identify several simple, locally-generated interventions that could support this community in the face of an insidious complex of non-nutritious food and fatal or debilitating infectious diseases such as the five species of human malaria (Singh and Daneshvar 2013; MMV 2015).

As women's interpretations of disease risk and vulnerability suggest (Halvorson et al. 2011; Halvorson 2004, 2003), the broader context of seasonal nutritional deficiencies, livelihood dislocations, and agricultural impoverishment all contribute to constraints on the management of malaria and other health risks. The focus here is on women owing to the centrality of women's agency personally, socially,
Table 1 Social and health development indicators for Kenya

Data Source: UNICEF (2013)

\begin{tabular}{ll}
\hline Total population (000) & $43,178.1$ \\
Urban population 2012 & $24.4 \%$ \\
Rural population & $75.6 \%$ \\
Births (000) per year & 1534.9 \\
Under-five mortality rate 2012 & 108,000 \\
Neonatal mortality rate (per 1000 live births) & 27 \\
Underweight prevalence in children under 5 years, 2008-2012, urban & $10.3 \%$ \\
Underweight prevalence in children under 5 years, 2008-2012 & $17.3 \%$ \\
Population living below poverty line (USD 1.25 per day) & $43.4 \%$ \\
Annual per capita income 2012 & $840 \mathrm{USD}$ \\
Youth (15-24 years) literacy rate 2008-2012 male & $83.2 \%$ \\
Youth (15-24 years) literacy rate 2008-2012 female & $81.6 \%$ \\
Total adult literacy rate 2008-2012 & $72.2 \%$ \\
Adult literacy rate: females as a $\%$ of males 2008-2012 & $85.6 \%$ \\
Use of improved sanitation facilities 2011 total & $29.4 \%$ \\
Use of improved sanitation facilities urban & $31.1 \%$ \\
Use of improved sanitation facilities 2011 rural & $28.8 \%$ \\
\hline
\end{tabular}


culturally, and economically as caregivers to malaria patients, as sustainers of their own risks during pregnancy (spontaneous abortions, stillbirths, death) (Sharma 2009; Singh et al. 2005), and as leaders of disease risk interventions. Their local perceptions of well-being and health risks are compelling because they reflect wider health and development circumstances at this point in time and because they raise important questions about how the health and malaria problems faced by the population can be addressed in a region increasingly marginalized within the framework of Kenya's national development priorities.

\section{Background: A geography of health, dietary and environmental demise}

In Kakamega County, health reflects a complex mosaic of intertwining factors, including the collapse of traditional diets, introduced grains, invasive plants, tropical equatorial climate, the human-built environment, disease risks, and local knowledge. The best way to understand how infectious diseases interact with under-nutrition and how under-nutrition affects systemic resistance to malaria is to look historically at diet in this malaria endemic area. The historical diets were complex, nutritionally dense and diverse, reflecting self-sufficiency and indigenous knowledge on how to eat richly without destroying the ecosystem. Diverse nutritional sources came from hunting vertebrate animals and gathering some invertebrates such as insect larvae along with roots, berries, seeds, and other wild fruits (Woodward 2014). Starting around 1925, the British colonial administration set forth an entirely new agricultural agenda "to develop agricultural efficiency in the native areas" that was based on corn from the Americas (Parker 1952, p. 125). In less than 50 years corn (Zea mais) became the backbone of the rural Kenyan diet and the agricultural economy. Today post-colonial Kakamega County is cleared of its tropical rainforest and agriculturally, infrastructurally, and psychologically dependent on the largescale mono-cropping of an introduced grain. ${ }^{3}$

\footnotetext{
${ }^{3}$ Dietary and Cropping System History. The adoption of corn led to complete alterations in the agricultural economic and indigenous diet. Traditional grains such as fonio (Digitaria spp.), millet (Panicum miliaceum) and sorghum (Sorghum bicolor) were nearly or entirely abandoned. These traditional
}

We contend that the ideal environmental conditions were created for two distinct yet inter-related processes: (one) a chronic and acutely fatal human disease in the form of malaria to gain a foothold in the population (Friedman et al. 2005); and (two) for an insidious parasitic weed known as striga (Striga hermonthica, S. asiatica, S. aspera, S. forbesii) ${ }^{4}$ to invade the cornfields (Watt 1936; Khan et al. 2006; Atuti Atera et al. 2013). As this article unfolds, we make the case that the British agricultural advisors'

\section{Footnote 3 continued}

grains were comparatively more difficult to harvest in large quantities given that their tiny seeds are in a splayed inflorescence rather than corn with hundreds of large compact kernels held on a cob contained in a single husk. Unfortunately, corn as a primary food is nutritionally deficient: it is missing two of the essential amino acids (lysine and tryptophan) for normal physical and cognitive development (FAO 1992). Corn contributed to a nutritionally-compromised population living with soils increasingly depleted of nutrients required for vigorous growth and development of both corn and the communities consuming the corn.

${ }^{4}$ Striga and malaria synergistically debilitate the smallholder farmer in this area of Kenya. Chronic forms of malaria and acute fatal forms of malaria especially affecting young children interrupts field work of the parents just at the time that striga weeds should be removed from the field. Striga removal is a painstaking process of hoeing and carefully pulling the weed from the living corn plant host. The more striga the poorer the harvest, the less cash for seeking diagnosis and medication, and the less available food causing greater under-nutrition. Undernutrition weakens the ability of the body to resist malaria. Striga, Striga hermonthica has been a problem in the farm fields of western Kenya since 1936 (Watt 1936; Khan et al. 2006). During the last 20-30 years, it has attained devastating proportions due to cereal mono-cropping (Oswald 2005). Now striga has gained a foothold in the cornfields of these women and their families. Striga, within a year can decrease corn production by $50 \%$ (Atuti Atera et al. 2013). To rid their field of striga, farmers have to lay their land fallow for 10 years or do daily back-breaking hoeing to physically pull the parasitic weed from the young corn plant, usually severely injuring the corn plant. The symptoms on corn are difficult to distinguish from those caused by lack of water (drought), like wilting and curling of leaves at an early stage. The infected plant may also show stunting and a pronounced burning of the leaf borders. The leaves are 'burnt' when the parasitic weed dominates over the corn plant. Striga weeds are difficult to control once they are established on a corn plant because they get their nutrients from the corn and literally grow on the corn plant. There is a small window when the hoeing and hand weeding must be done (between the time when the striga is visible and striga plants start to flower). If malaria keeps the farmer out of the field in that small window, the farmer has compromised her corn yield and the cycle of under-nutrition and low cash flow continues the vulnerability the farmer and her family to malaria. 
push to increase corn production in this part of Kenya laid the foundation for dependence on a largely cornbased diet. The resulting level of under-nutrition has led to a population less able to resist malaria. The timing of farmers' efforts to control this highly invasive parasitic weed coincides with the malaria season when malaria is sapping the energy and health of farmers who are also the mothers and primary caregivers of children suffering and dying from malaria.

Our research team confirmed additional factors that have also converged in Kakamega County to foster transmission of malaria. First, numerous informal conversations and observations revealed that open defecation is widely practiced. During the wet season, bacteria in the fecal material proliferate in semi-permanent still bodies of water, exactly what female anopheline mosquitoes need for robust larval development of their offspring. Second, the growing human population increases the frequency of these ideal larval breeding pools, and provides the requisite human incubators for sustaining the malaria-causing microorganisms (protozoans). Our field observations also indicated that morning and evening meals are consumed inside homes during peak anopheline biting times (Yohannes and Boelee 2012; Harris et al. 2006). Residents are even at risk in the newer forms of house and building construction because the gap we found between the walls and the roof encourages air circulation which also allows for mosquito entrance. Third, female anopheline mosquitoes have relatively quickly evolved behaviors to find humans on which they rely for a blood meal to mature their eggs (Gatton et al. 2013). We suggest that the protozoan populations, dependent on the female anopheline mosquito to incubate their own offspring, evolutionarily likely influenced this behavior given that the malaria protozoan needs both the human and the adult mosquito to survive and reproduce.

The complexity of the malaria vector-human relationship is daunting. We propose that nutritionallycompromised farmers are laboring against striga in their fields during the rainy season at the very time when anopheline mosquitoes carrying malaria are finding many places to breed and opportunities to transmit malaria. Without the knowledge of this detailed biological cycle or nutritional deficits, farmers and their families are caught in the current complex system of disease, under-nutrition, and crop failure which contributes to chronic material poverty.

In parts of Kenya, malaria elimination has been successful with a combination of national support and community-based action especially in tourist destinations along the coast and surrounding the capital city of Nairobi. The Western Province, however, is not a popular tourist destination, and national and regional attention to malaria elimination has not been directed there (Gitonga et al. 2010). In the Western Province, a recent study found that $21 \%$ of 3892 school children tested positive (using slide microscopy) for malaria, which is over twice as high as any other province in Kenya (Gitonga et al. 2010). In 2012, Kakamega County reported 232,383 children under five presenting with clinical malaria, the highest number for any county in Kenya and $37 \%$ higher than the next highest county (KNBS 2012). For these reasons, we focused our study in this epidemic and high malaria transmission area that is home of the Luhya ${ }^{5}$ ethnic group.

Interestingly, there is an array of research and nongovernmental organizations that have actively engaged with local residents to address agricultural and environmental quality problems in Kakamega County. For example microbiologists Sands et al. (2015) have collaborated with women farmers to eliminate the parasitic weed striga that is threatening their mono-cropped corn. The Agriculture and Climate Risk Enterprise, known as One Acre, is a private commercial company launched in 2014 by The Syngenta Foundation and has focused on experiential learning, microcredit, and seeding and fertilizing regimes to farmers (Thurow 2012). Since 2004 the Montana State University-based chapter of Engineers Without Borders has responded to local requests for access to clean water and sanitation at elementary schools (Engineers Without Borders 2015). While issues of clean water and crop production are being addressed, the intertwined health issues of undernutrition and malaria management continue to be

\footnotetext{
${ }_{5}$ Luhya is the mother tongue in this research setting. English along with Swahili are exclusively learned and used in school settings, and students are punished for speaking Luhya in school. No written material is given out in Eschinutsa or Khwisero Health Centers. Signs regarding clinic services are only in English. All health information from Western science origins comes to community through public school.
} 
neglected. We chose to begin a holistic process ${ }^{6}$ of engagement to reach quickly into an understanding of the deep, underlying perceptions and motivations of women in this area.

\section{Research site}

This study was undertaken in a dispersed community surrounding the town of Eshinutsa along the Yala River (latitude $00^{\circ} 10^{\prime} 00^{\prime \prime} \mathrm{N}$; longitude $34^{\circ} 36^{\prime} 00^{\prime \prime} \mathrm{E}$ ) which is $50 \mathrm{~km}$ northeast of Lake Victoria (Fig. 1). The Yala River flows from the Mau forest complex into the Winam Gulf of Lake Victoria. The hydroclimatic region of equatorial Kenya in combination with the riverine environment and the agricultural activity create abundant opportunities for malariabearing female mosquitoes to rear their larvae. This study site was selected first because it is representative of rural communities where over $75 \%$ of Kenyans reside (UNICEF 2013). Second, the rural settlement is relatively similar to the community of Mali where, using the holistic process, villagers initiated villagebased malaria management that led to the local elimination of cerebral malaria (Dunkel et al. 2013). And third, a long history of trust and respect built up between residents and MSU Engineers Without Borders (EWB) created a platform for our interaction with this locale and the opportunity for one of the authors (Hansen) to live with a local family during field research.

A recent baseline survey suggests that approximately 204 families with a mean of six children per household and 1629 people live in the Eshinutsa area (Khwisero District, Kakamega County) (Roless Media and Management Institute 2010). The majority of these residents are subsistence farmers. Few other employment and professional opportunities exist to gain cash income to purchase luxuries such as bread and jam, clothes, and shoes in the market. Family farms are the primary source of food, with the main crops being maize, beans, bananas, sweet potatoes,

\footnotetext{
${ }^{6}$ The holistic process has three basic steps. First, the community-of-focus defines their most important values/goals. Second, the community enumerates current resources to maintain these values and describes how they produce these resources. Third, the community determines what future resources are needed to sustain these values and if they will need other ways to produce these resources.
}

groundnuts, and cassava. There are two wet seasons: March to July (long rains) and August to November (short rains) (Omyonga 2014). Obtaining adequate water quantity is not a major challenge, yet acquiring clean potable water is difficult (Roless Media and Management Institute 2010). Wells are mostly shallow hand dug and unprotected with depths generally 6-8 $\mathrm{m}$ deep. These shallow wells which are commonly found on school grounds and on wealthier home sites are contaminated with Escherichia coli which is ideal for rearing larvae of anopheline mosquitoes. Deep-water borehole wells do filter contaminants such as bacteria, but are only present where they were introduced by MSU Engineers Without Borders. Otherwise, water comes from contaminated springs or the river. Irrigation is minimal and done manually by individual subsistence farmers (Roless Media and Management Institute 2010). Water is also used in this area to make the mud bricks used to construct houses. Brick-making causes small pools of still water, thereby creating additional habitats for anopheline mosquito larvae to develop.

\section{Data sources, methods, and approach}

Demographics of sample population

We focused our study on women because women are the main care-givers of young children-the most atrisk group for malaria; they grow, store, and prepare food; and they are the main caretakers of community health. Women, mainly mothers, ages $18-86$ served as study participants (mean $=40.5$ years) (Table 2). Of the women we interviewed, $83.6 \%$ self-identified as subsistence farmers (Table 1) and the remaining study participants identified themselves as student, community health worker, teacher, and what is locally referred to as "business lady" (Table 2). Farms are usually owned and operated by a husband and wife couple that supports their children, and at times grandparents and other extended family members.

Interviews and survey methods

In-depth interviews were conducted with 60 women living in the area surrounding the Eshinutsa Primary School. Interviews were conducted in respondents' 


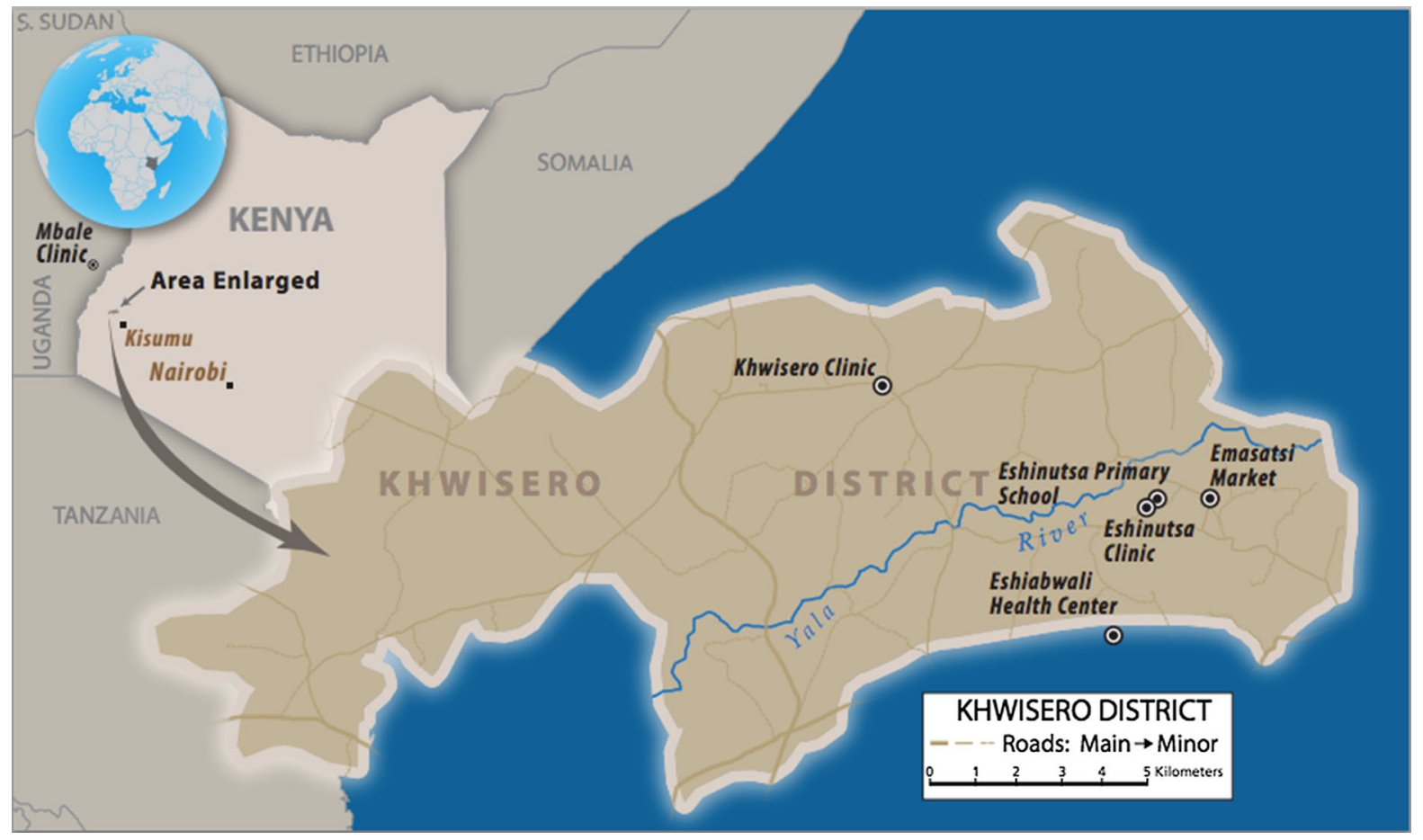

Fig. 1 Roads, health centers, and river in Khwisero District (Map source: drawn by J. Robertson 2014 Cairn Cartography, Missoula, Montana)

homes. Structured spot observations were made of daily routines in relation to peak mosquito biting time and mosquito-proof conditions of doors and windows of homes. Living areas and community gathering areas were also examined for malaria-specific health risks and any impact they may have on health. Participant observations were recorded while one of the authors (Hansen) lived there for 5 weeks of fieldwork.

Our interview methods were based on those of a study of local knowledge on water quality and waterborne illness in Mali (Halvorson et al. 2011). Questions were developed to follow the holistic process (Dunkel et al. 2013 modified from Savory and Butterfield 1999) and were based on community interaction methods developed in Mali by Dunkel et al. (2013). These methods are credited for a sustained local elimination of cerebral malaria by Malian villagers themselves. This process establishes community-based malaria management and draws upon sustainable resources the community has to manage malaria without external assistance.

The interview questions were designed to explore perceptions and motivations regarding life (Table 3 ) and health (Table 4). Verbal and written consent to participate in the study was given by all study participants in Luhya. Luhya is the mother tongue in this community in which few women have had the opportunity to learn Kenya's national languages, English and Swahili. Literacy and fluency in English is the path to obtain Western science health information in Kakamega County. Interviewees were asked 22 questions addressing household demographics, desired quality of life, health issues, local healthcare, and understanding of the disease ecology of malaria and the mosquito vector, malaria prevention techniques, and malaria treatment. Questions were translated into Luhya by two translators from the Eshinutsa area. Responses were recorded via tape recording and written record. Question order was kept constant. Additional questions were used to probe and clarify issues and responses.

In addition to the interviews with local women, structured conversations were conducted at the Eshinutsa Health Center with the public health personnel, including the community health educator and the registered nurse. Other methods included 
Table 2 Age distribution and professions ${ }^{\mathrm{a}}$ of 60 women interviewees in Eshinutsa area of Khwisero District, western Kenya (mean years of formal education $=6.5$ )

\begin{tabular}{ll}
\hline Age range & Number of people \\
\hline $18-22^{\mathrm{a}}$ & 5 \\
$23-27^{\mathrm{a}}$ & 7 \\
$28-32^{\mathrm{a}}$ & 9 \\
$33-37^{\mathrm{a}}$ & 9 \\
$38-42^{\mathrm{a}}$ & 6 \\
$43-47^{\mathrm{b}}$ & 8 \\
$48-52^{\mathrm{b}}$ & 6 \\
$53-57^{\mathrm{b}}$ & 3 \\
$58-62^{\mathrm{b}}$ & 2 \\
$63-67^{\mathrm{c}}$ & 1 \\
$68-72^{\mathrm{c}}$ & 2 \\
$73-77$ & 0 \\
$78-82$ & 0 \\
$83-87^{\mathrm{c}}$ & 2 \\
\hline
\end{tabular}

${ }^{a}$ In age range $18-40$ years were: 29 women $(85.3 \%)$ farmers: $2(5.9 \%)$ students; a tailor, tailor, Community Health Worker, and owner/operator of a hair salon (each $2.9 \%$ ). Mean years of formal education was 7.9; 41-63 age group 5.6; and 64-86 age group 0

b In age range 41-63 years were: 17 (77.3\%) farmers; 2 $(9.1 \%)$ "business ladies," i.e., ran small store in front of their house in a stall, a market stall, or sell from plot of market ground (no structure) on weekly market day; 2 (9.1\%) teachers; one $(4.5 \%)$ Community Health Worker

c All of these women were farmers without other professions or formal education

conversations with local residents, participant observation and community walks.

Data analysis

The quantitative data generated through the interview process was tabulated and summarized. Chi-square analysis was conducted using SPSS (IBM Corp 2013) to compare women's current understanding of malaria, its transmission by the mosquito species complex, An. gambiae sensu latu, as well as Anopheles funestus s.l., and Anopheles coustani and motivations to manage malaria. To further differentiate women's understanding of malaria, responses to five questions were analyzed on the basis of age groupings as follows: 18-40, 41-63 and 64-86 years. When multiple study participants gave the same response to a question, these were tallied within and across age groups. The qualitative data generated through interviewing was coded for themes and nuances of perceptions and motivations. To probe deeper into the relationship of the percent and frequency of women's number of years of formal education and their understanding of human malaria transmission, a cross tabulation of knowledge and years in school was reported and a Chi-square analysis conducted.

\section{Results}

The results of this study point to a serious chasm existing between millions of dollars spent in Kenya on malaria prevention and surveillance and actual knowledge and understanding of the disease etiology and biology among community members at risk for malaria. Without this understanding throughout the community, Western science solutions to managing the mosquito and the disease by those at risk remain misunderstood.

On one side of the chasm are Western-trained epidemiologists and medical personnel who know the scientifically proven ways to manage the vector and the disease. On the other side of the chasm are Kenyan communities that have no point of reference or knowledge framework for understanding key dimensions of this disease. Understandings that are missing include: (a) the complex life cycle of the malariacausing protozoans who use the female Anopheles mosquitoes as incubators for the reproduction of more protozoans that cause malaria; (b) what the entire life cycle of malaria-carrying mosquitoes entails; (c) the relationship between malaria resistance and the nutrient-deficient, but typical, diet of rural Kenyans at high risk for malaria (Deribew et al. 2010; Ehrhardt et al. 2006; Ferreira et al. 2015; Glinz et al. 2014, 2015; Maketa et al. 2015; Mbug et al. 2010).

Perceptions and knowledge of malaria transmission paths, and management

According to the interview data and our observations, community members in this part of Kenya accept malaria as a part of life. Malaria was not part of neighborhood discussions during the latter part of the "long rains" (the main wet season) during peak malaria transmission. Malaria was perceived as "the most difficult health issue to avoid" for 27 of the 60 
Table 3 Responses of rural Luhya women, Khwisero District (Kakamega County) western Kenya to Quality of Life question: "What is important in life to make life good?"

\begin{tabular}{|c|c|c|c|c|}
\hline \multirow[t]{2}{*}{ Response $^{\mathrm{a}}$} & \multicolumn{4}{|c|}{ Frequency (percent mentioning) } \\
\hline & $18-40$ y.o. $(N=33)$ & $41-63$ y.o. $(N=22)$ & $64-86$ у.о. $(N=5)$ & Total $(N=60)$ \\
\hline Job/business/employment ${ }^{\mathrm{b}}$ & $23(67.6)$ & $10(45.5)$ & $1(20)$ & $34(55.7)$ \\
\hline Farming $^{\mathrm{b}}$ & $8(23.5)$ & $8(36.4)$ & $1(20)$ & $17(27.9)$ \\
\hline Education of children & $6(17.6)$ & $7(31.8)$ & $1(20)$ & $14(23.0)$ \\
\hline Health & $3(8.8)$ & $3(13.6)$ & $1(20)$ & $7(11.5)$ \\
\hline Food $^{\mathrm{c}}$ & $2(5.9)$ & $3(13.6)$ & $1(20)$ & $6(9.8)$ \\
\hline Living without stress & $1(2.9)$ & $0(0)$ & $1(20)$ & $2(3.3)$ \\
\hline Life, simply being alive & $0(0)$ & $2(9.1)$ & $0(0)$ & $2(3.3)$ \\
\hline $\mathrm{Tea}^{\mathrm{d}}$ & $0(0)$ & $1(4.5)$ & $1(20)$ & $2(3.3)$ \\
\hline
\end{tabular}

${ }^{a}$ Responses mentioned by one person each: exercise, diet, hygiene, water, everything, good latrine, having your own living, good shelter

b Job/business/employment is extremely rare, not farming, and a way to produce cash. Income generating opportunities viewed culturally appropriate for women include: nurse; midwife; teacher; school principal; selling farm produce and/or handicrafts. A broader range of off-farm employment and income generating opportunities are available to men than women and include: school teacher, principal; government official; blacksmith, brick-maker; store owner; leaser of land to others; contractor; sell produce and handicrafts from one's farm or home. In the holistic process (Savory and Butterfield 1999), job, business, employment, farming are forms of production of resources such as cash or trade used to attain one's quality of life. Status, fame, or achievement is a desired quality of life resulting from employment outside of farming. Complexities of translation during the interviews could have missed this carefully nuanced statement

${ }^{c}$ Ugali and food were combined. Ugali is a staple dish made primarily from cornmeal that is cooked in boiling water into a thick consistency and eaten with all Luhya meals

d Black tea with whole cow's milk and light brown sugar

(45\%) of the interviewees (Table 5). When asked the question directly about whether malaria is a "big problem," 55 of the $60(91.6 \%)$ women said it was for themselves, their family, and/or for their community. The other five study respondents, all of them in the youngest age group, mentioned that malaria is "not a problem at all." Importantly, fifty-five respondents had direct personal experience with malaria, having either a family member or themselves contracted the disease. Ninety-six percent of the women recognized that malaria can be fatal.

The key to eliminating malaria locally is for those at risk to understand the transmission path details and to understand that malaria can be eliminated. Respondents were asked, How do you contract malaria? The scientifically correct response is that you must be "bit by," i.e., have a blood meal taken from you by, a female Anopheles mosquito about 8 days after she has taken a blood meal from another person in the fever stage of malaria (Table 6). During the fever stage the human's peripheral blood will contain the protozoan causing malaria and this will be pulled into the mosquito's gut along with the blood meal. Importantly, no respondent gave a completely correct answer. Most respondents (54\%) gave incorrect responses on how malaria is transmitted. Forty-six percent of responses were partially accurate and included the following: mosquito bites, the female Anopheles, and mosquito. The most common responses to this question were: mosquito bites; not sleeping under a bed net; the female Anopheles; I don't know; and from the rain. Other frequent responses to how to contract malaria referenced specific environmental conditions or agricultural phenomena: heavy rains, bush areas, when maize are flowering, and pollen grains can cause some malaria. Missing from all of the interviews were specific details pertaining to where malaria originates (another human), what the protozoan is doing (reproducing in the mosquito female and in the human), and what the role of the female mosquito is in the transmission process.

In order to avoid contracting malaria, the women reported using bed nets, avoiding stagnant water, slashing the brush around the compound, and taking "tablets" (Table 6). Seventy-six percent of the women did not recognize that during the daytime a person sick 
Table 4 Responses of rural Luhya women, Khwisero District (Kakamega County) western Kenya to "What do you do to be healthy?"

\begin{tabular}{|c|c|c|c|c|}
\hline \multirow[t]{2}{*}{ Response $^{\mathrm{a}}$} & \multicolumn{4}{|c|}{ Frequency (percent mentioning) } \\
\hline & $18-40$ у.о. $(N=33)$ & $41-63$ y.o. $(N=22)$ & $64-86$ у.о. $(N=5)$ & Total $(N=60)$ \\
\hline Balanced diet & $12(35.3)$ & $4(18.2)$ & $2(40)$ & $18(29.5)$ \\
\hline Food $^{\text {b }}$ & $4(11.8)$ & $10(45.5)$ & $0(0)$ & $14(23.0)$ \\
\hline Clean environment ${ }^{\mathrm{c}}$ & $7(14)$ & $4(11.1)$ & $1(20)$ & $12(12.5)$ \\
\hline Clinic & $5(2)$ & $3(8.3)$ & $1(20)$ & $9(9.4)$ \\
\hline Exercise & $5(2)$ & $2(5.6)$ & $0(0)$ & $7(7.3)$ \\
\hline Hygiene environment ${ }^{\mathrm{d}}$ & $3(6)$ & $1(2.8)$ & $1(20)$ & $5(5.2)$ \\
\hline Clean water & $3(6)$ & $1(2.8)$ & $0(0)$ & $4(4.2)$ \\
\hline Farming & $0(0)$ & $4(11.1)$ & $0(0)$ & $4(4.2)$ \\
\hline Clean food & $2(4)$ & $0(0)$ & $1(20)$ & $3(3.1)$ \\
\hline Medicine & $0(0)$ & $2(5.6)$ & $1(20)$ & $3(3.1)$ \\
\hline Sleep under net & $2(4)$ & $0(0)$ & $0(0)$ & $2(2.1)$ \\
\hline Business & $2(4)$ & $0(0)$ & $0(0)$ & $2(2.1)$ \\
\hline No stress & $1(2)$ & $1(2.8)$ & $0(0)$ & $2(2.1)$ \\
\hline I don't know & $0(0)$ & $1(2.8)$ & $1(20)$ & $2(2.1)$ \\
\hline
\end{tabular}

${ }^{\text {a }}$ Responses mentioned each by one person: healthy, good dressing, keep busy with manual house work, protection from cooking fire, clean vegetables, work, brush teeth, wash clothes, protection from AIDS

b Food, ugali, fruit, and eat were combined into one category: food

c Clean environment, cleanliness were combined into clean environment

d Take shower and hygiene were combined under hygiene

Table 5 Responses of women interviewees to "Which health issues are most difficult to avoid?"

\begin{tabular}{lllll}
\hline Disease $^{\mathrm{a}}$ & \multicolumn{4}{l}{ Frequency (percent mentioning) } \\
\cline { 2 - 5 } & $18-40$ y.o. $(N=33)$ & $41-63$ y.o. $(N=22)$ & $64-86$ y.o. $(N=5)$ & Total $(N=60)$ \\
\hline Malaria & $14(27.5)$ & $10(35.7)$ & $3(50)$ & $27(31.8)$ \\
HIV/AIDS & $14(27.5)$ & $10(35.7)$ & $0(0)$ & $24(28.2)$ \\
Cancer & $5(9.8)$ & $1(3.6)$ & $0(0)$ & $6(7.1)$ \\
Typhoid & $6(11.7)$ & $1(3.6)$ & $1(16.7)$ & $8(9.4)$ \\
Diabetes & $2(3.9)$ & $1(3.6)$ & $0(0)$ & $5(3.5)$ \\
Not known & $2(3.9)$ & $1(3.6)$ & $2(33.3)$ & $5(5.9)$ \\
Diarrhea & $2(3.9)$ & $0(0)$ & $0(0)$ & $2(2.4)$
\end{tabular}

${ }^{a}$ Responses mentioned by total of one person: blood pressure, none, pneumonia, meningitis, cerebral malaria, chest pain, joint pain, tuberculosis, cholera, fever

with malaria should use a bed net to prevent mosquitoes from obtaining the malaria-causing protozoans and then transmitting malaria to other people. Of those interviewed, $95 \%$ reported owning a bed net and $85 \%$ reported using the bed net during the night before the interview.
Chi-square analysis results indicated that study participants' understanding of malaria based on the four questions was not significantly different among age groups (Table 6). Nearly all interviewees $(N=58$ or $98 \%$ ), regardless of age group, indicated they or someone in their family had contracted malaria. 
Table 6 Perceptions and local knowledge of malaria shared by women in Eschinutsa area in Khwisero District, Western Region of Kenya

Question

\begin{tabular}{llll}
\multicolumn{2}{l}{ Frequency of response (percent mentioning) } \\
\hline $18-40$ y.o. & $41-63$ y.o. & $64-86$ y.o. & Total \\
$(N=33)$ & $(N=22)$ & $(N=5)$ & $(N=60)$
\end{tabular}

How do you contract malaria?

Mosquito bites

21

Not sleeping under a net

Female Anopheles

I don't know

Rain

Mosquito

Fever/cold

Climate

Inhale dust

Stagnant water

Insects

Don't use lifestraw ${ }^{\mathrm{a}}$

Bushy areas

Maize flowering

Contaminated water

How do you keep from getting malaria?

Bed net

Slash

Avoid stagnant water

Tablets

Clean water

None

Stay in house at evening

Wash hands after latrine

SP Tablet

Don't know

Avoid bushy area

Medicine

Artemether lumefantrine (AL Tablets)

Clean compound

Mosquito powder (BOOM)

Heavy clothes to avoid being chilly

Cleanliness

Walk during rainy season

Exercise

Eating

Dressing

Pullover, shoes after rain

Drink hot water
10

4

$$
2
$$$$
2
$$

4

4

2

3

0

0

$$
0
$$$$
0
$$$$
0
$$$$
1
$$$$
1
$$$$
1
$$

15

2

$$
0
$$$$
0
$$$$
3
$$$$
1
$$$$
1
$$$$
2
$$$$
1
$$$$
0
$$$$
0
$$$$
0
$$$$
0
$$$$
0
$$$$
0
$$$$
0
$$$$
0
$$$$
\begin{aligned}
& 0 \\
& 0
\end{aligned}
$$$$
0
$$$$
1
$$$$
1
$$$$
1
$$$$
1
$$

1
0

34

11

8

8

6

4

4

1

$$
1
$$$$
1
$$$$
1
$$$$
1
$$$$
\begin{aligned}
& 1 \\
& 1
\end{aligned}
$$$$
1
$$$$
1
$$ 
Table 6 continued

Question

Frequency of response (percent mentioning)

\begin{tabular}{llll}
\hline $18-40$ y.o. & $41-63$ y.o. & $64-86$ y.o. & Total \\
$(N=33)$ & $(N=22)$ & $(N=5)$ & $(N=60)$
\end{tabular}

What do you do when sick with malaria?

$(N=33)$

$(N=22)$

$(N=5)$

$(N=60)$

Clinic/doctor/health center/hospital

Tablets

28

Artemether lumefantrine (AL Tablets)

Panadrol

Blood test

Quinine

Maloda

Fancide (Fansidar)

Sonamoja

I don't know

Painkiller

Metakelvin

Hot water

Symptoms of malaria ${ }^{\mathrm{b}}$

Headache $^{\mathrm{c}}$

Chilly/body temperature lowers/hands and feet cold/ cold $^{\mathrm{c}}$

Fever/Increase of body temperature ${ }^{\mathrm{c}}$

Vomiting ${ }^{\mathrm{c}}$

Joint ache

Stomach ache ${ }^{\mathrm{c}}$

Loss of appetite

Shiver

Weak

Diarrhea $^{\mathrm{c}}$

Dizzy/nausea $^{\mathrm{c}}$

Cough

Sneezing

I don't know

Chest pain

Bad health

Taste in mouth different

Goes and comes back

Sweating $^{\mathrm{c}}$

Eyes yellow ${ }^{\mathrm{c}}$

Backache

Lose weight

Uneasy

Body rough

Skin shrinks

Rash

Tired
2

2

2

0

0

0

1

1

1

1

0

12

13

11

7

6

5

1

3

3

3

2

1

2

0

1

1

1

1

1

1

1

1

0

0

0

0
17

11

2

\section{1}

\section{1}

2

2

2

0

0$$
0
$$$$
0
$$$$
0
$$$$
1
$$

12

35

23

23

17

10

8

6

6

5

5

4

4

2

2

2 
Table 6 continued

\begin{tabular}{|c|c|c|c|c|}
\hline \multirow[t]{2}{*}{ Question } & \multicolumn{4}{|c|}{ Frequency of response (percent mentioning) } \\
\hline & $\begin{array}{l}18-40 \text { y.o. } \\
(N=33)\end{array}$ & $\begin{array}{l}41-63 \text { y.o. } \\
(N=22)\end{array}$ & $\begin{array}{l}64-86 \text { y.o. } \\
(N=5)\end{array}$ & $\begin{array}{l}\text { Total } \\
(N=60)\end{array}$ \\
\hline Body ache ${ }^{\mathrm{c}}$ & 0 & 0 & 1 & 1 \\
\hline \multicolumn{5}{|l|}{ Can malaria go away and come back? } \\
\hline Comes back & 26 & 17 & 4 & 47 \\
\hline No & 4 & 4 & 1 & 9 \\
\hline Comes back if you had bad treatment & 1 & 2 & 0 & 3 \\
\hline Comes back if you didn't take the whole dose & 1 & 2 & 0 & 3 \\
\hline Long time to come back & 1 & 0 & 0 & 1 \\
\hline Possibly comes back & 1 & 0 & 0 & 1 \\
\hline Comes back after treatment & 0 & 1 & 0 & 1 \\
\hline \multicolumn{5}{|l|}{ What are different types of malaria? ${ }^{\mathrm{b}}$} \\
\hline None/only one type of malaria & 13 & 6 & 3 & 22 \\
\hline Pneumonia & 9 & 5 & 0 & 14 \\
\hline Cerebral malaria & 8 & 3 & 0 & 11 \\
\hline Don't know & 5 & 2 & 1 & 8 \\
\hline Meningitis & 2 & 2 & 0 & 4 \\
\hline Chilly, shivering malaria & 1 & 1 & 1 & 3 \\
\hline Typhoid & 1 & 1 & 0 & 2 \\
\hline Headache & 1 & 1 & 0 & 2 \\
\hline Joint malaria & 2 & 0 & 0 & 2 \\
\hline Malaria without headache & 1 & 0 & 0 & 1 \\
\hline Just-tired-and-can't-work malaria & 1 & 0 & 0 & 1 \\
\hline Strong malaria & 1 & 0 & 0 & 1 \\
\hline Normal malaria & 1 & 0 & 0 & 1 \\
\hline Complicated malaria & 1 & 0 & 0 & 1 \\
\hline Anemia & 1 & 0 & 0 & 1 \\
\hline Chronic malaria & 0 & 1 & 0 & 1 \\
\hline
\end{tabular}

${ }^{a}$ Lifestraw is a simple water purification system used in rural Kenya

b Malaria types and malaria symptoms mentioned by total of one person: symptoms differ; malaria of the chest; yellow fever; sneezing; rashes; scratching; diarrhea

c Physical findings for malaria listed by CDC: elevated temperatures; perspiration; weakness; enlarged spleen; mild jaundice; enlargement of the liver; and increased respiratory rate. Common symptoms listed by CDC: fever; chills; sweats; headaches; nausea and vomiting; body aches; general malaise

Ninety percent of women across age groups indicated they felt they received good health care (Table 7). The majority of respondents-those ages $18-41(80 \%)$ and in the 41-63 (55\%)-indicated they did not use medicinal plants to control malaria. However, $60 \%$ of the women aged 64 or older indicated they did use medicinal plants. The majority of women across age groups answered "Yes" (84\%) to the question about whether malaria can "come back" or reoccur without reinfection by a mosquito.
Without a complete understanding of how malaria is transmitted, we have observed in other communities that malaria elimination fails (Dunkel et al. 2013). Based on the cross-tabulation results, women interviewed had a partial understanding of the causes and transmission pattern of malaria from human to human with the assistance of a female mosquito. Of the women with 0 years of formal education, $53.8 \%$ gave an incorrect response while $46.2 \%$ gave a correct response. Similarly, $45.5 \%$ of women with 1-6 years 
Table 7 Women's perception of healthcare in Khwisero District, Western Region, Kenya

\begin{tabular}{|c|c|c|c|c|}
\hline \multirow[t]{2}{*}{ Question } & \multicolumn{4}{|c|}{ Frequency of response } \\
\hline & $\begin{array}{l}18-40 \text { y.o. } \\
(N=33)\end{array}$ & $\begin{array}{l}41-63 \text { y.o. } \\
(N=22)\end{array}$ & $\begin{array}{l}64-86 \text { y.o. } \\
(N=5)\end{array}$ & $\begin{array}{l}\text { Total } \\
(N=60)\end{array}$ \\
\hline \multicolumn{5}{|l|}{ Do you feel like you get good healthcare? } \\
\hline Yes & 33 & 16 & 5 & 54 \\
\hline No & 0 & 3 & 0 & 3 \\
\hline Expensive & 0 & 3 & 0 & 3 \\
\hline Not expensive & 1 & 1 & 0 & 2 \\
\hline Drugs not available sometimes & 1 & 0 & 0 & 1 \\
\hline No power to get good healthcare, wants it & 1 & 0 & 0 & 1 \\
\hline Access difficult & 0 & 1 & 0 & 1 \\
\hline Yes if she buys medicine & 0 & 1 & 0 & 1 \\
\hline Yes in future & 0 & 1 & 0 & 1 \\
\hline Being sick is not fun & 0 & 1 & 0 & 1 \\
\hline Depends on money she has & 0 & 1 & 0 & 1 \\
\hline \multicolumn{5}{|l|}{ Is going to clinic too expensive? } \\
\hline Not expensive/cheap & 10 & 7 & 1 & 18 \\
\hline Expensive & 8 & 6 & 2 & 16 \\
\hline Private expensive & 3 & 0 & 0 & 3 \\
\hline Public cheap & 2 & 0 & 0 & 2 \\
\hline $\begin{array}{l}\text { Depends on place you go/some expensive, } \\
\text { some cheap }\end{array}$ & 0 & 1 & 1 & 2 \\
\hline Public doesn't always treat well & 1 & 0 & 0 & 1 \\
\hline Expensive depending on disease you have & 1 & 0 & 0 & 1 \\
\hline Between cheap and expensive & 1 & 0 & 0 & 1 \\
\hline About $20,000 \mathrm{KSH}(1 \mathrm{KSH}=0.011 \mathrm{USD})$ & 0 & 1 & 0 & 1 \\
\hline Varies, some blood tests are additional fee & 1 & 0 & 0 & 1 \\
\hline
\end{tabular}

of education gave an incorrect response while $54.5 \%$ identified a correct response for malarial transmission. Women with 7-8 and over 9 years of education had a much greater number of correct responses. Approximately $79 \%$ of women with 7-9 years of education and $70.6 \%$ of women with 9 years or more of education described correctly ways that malaria is transmitted. While a Chi-square analysis of the relationship between years of education and knowledge of malaria yielded a non-significant result $(p>.05)$ (Table 8), these results suggest that the more years of schooling women had the more they understood how malaria is transmitted.

When sickness with malaria presents itself, most indicated that they go to the clinic, doctor, health center, or hospital (Table 6). Some study participants reported taking various 'tablets' that are available locally without a prescription including: Panadrol;
Sonamoja; Artemether lumefantrine (AL Tablets); painkillers; Metakelvin; Quinine; Malarone and Fansidar. In the United States these medications require a prescription (MMV 2015). Medicinal plants were used by $33 \%$ of the women. Plants included leaves of cinchona, Artemisia annua, and aloe vera as well as unidentified plants either collected in the wild and/or obtained in the local market.

Malaria symptoms mentioned were chills, headache, vomiting, fever, and joint ache. Joint pain was frequently listed as a symptom of malaria, indicating confusion between dengue fever and malaria. Malaria was reported to go away and come back, but some suggested, "This could happen if you didn't get proper treatment or didn't take your medication properly." The fact that malaria can kill a person was indicated by $95 \%$ of interviewees. Many said there is only one type of malaria; others claimed pneumonia and cerebral 
Table 8 Percent and frequency of 60 women interviewees in Eshinutsa area of Khwisero District, Western Province Kenya by number of years of formal education who gave a correct answer about human malaria transmission

\begin{tabular}{llr}
\hline Years of formal education & \multicolumn{3}{l}{ Percent knowledge of malaria transmission (frequencies) } \\
\cline { 2 - 3 } & Incorrect & Correct \\
\hline 0 & $53.8(7)$ & $46.2(6)$ \\
$1-6$ & $45.5(5)$ & $54.5(6)$ \\
$7-8$ & $21.1(4)$ & $78.9(15)$ \\
$9-16$ & $29.4(5)$ & $70.6(12)$ \\
\hline
\end{tabular}

The Chi-square results are: $\chi_{(3)}^{2}=4.416, p=.220$

malaria were both types of malaria. Respondents overwhelmingly believed they received good healthcare in clinics and hospitals (Table 7), yet for half of the respondents the care and treatment associated with the private facilities were viewed as cost prohibitive.

An important part of malaria management is diagnosis and timely treatment. Forty-six of 55 $(83.6 \%)$ women who reported that they or a family member had suffered from malaria also reported that when sick with malaria they or a family member had a microscopic analysis; ${ }^{7}$ nine women or their immediate family members did not have a microscopic analysis. Eshinutsa Health Center, the closest clinic to the community, did not have a functional microscope or trained technician to analyze blood smears for malaria-causing protozoa. For malaria diagnosis and medications 51 of the 55 interviewees who had malaria chose to go to the Eshinutsa Health Center, whereas 10 chose no clinic, six visited the private Khwisero clinic $4 \mathrm{~km}$ away (20 min by motorbike), and six went to Mbale Hospital (45 min by motorbike). Private clinics

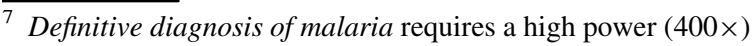
oil immersion microscope to observe blood cells from patient. Blood from the patient is applied to a glass slide and stained with Giemsa. Rapid Diagnostic Test (RDT) is an alternate way of quickly diagnosing malaria by detecting specific malaria antigens in patient's blood. A blood specimen collected from the patient is applied to the sample pad on the test card along with certain reagents. After 15 min, presence of specific bands in test card window indicate if patient is infected with Plasmodium falciparum or one of other 3 human malaria species. A blood supply of $P$. falciparum is needed as a positive control. Positive RDTs should be followed by microscopy. Currently approved RDTs detect 2 different malaria antigens; one is specific for $P$. falciparum and the other is found in all 4 human species of malaria. Microscopy is needed to determine malaria species detected by RDT. In addition, microscopy is needed to quantify proportions of red blood cells infected, an important prognostic indicator (Murray and Bennett 2009).
}

were perceived as more expensive than public clinics but considered to offer higher quality treatments than public clinics. Public clinics were considered affordable by interviewees, but not as trusted. Other clinics mentioned were the Luanda Market Hospital (30 min by motorbike), Eshiabwali Health Center (10 min by motorbike from the Eshinutsa Elementary School), a private hospital, and a health clinic in Elwangale (1 hr walk from Eshinutsa).

According to the Eshinutsa Health Center personnel, the leading diseases in the community were: respiratory, diarrhea, skin conditions; pneumonia; malaria during pregnancy; and general accidents. Malaria was not mentioned as a leading cause of childhood disease. When this study was conducted, 381 patients under five years of age and 761 patients over 5 years (including adults) were seen for various health problems at this clinic. Of these, 283 (74\%) cases were confirmed malaria in children under five years, and $517(68 \%)$ of those over 5 years had malaria. Without a microscope at this clinic, confirmation of these cases had to be made by a rapid diagnosis dipstick test or by a microscopic analysis at a local private clinic. When cerebral malaria, Plasmodium falciparum, was suspected, travel to a more well equipped clinic was typical. The nurse at Eshinutsa Health Clinic reported cerebral or severe malaria caused by $P$. falciparum was a common type of malaria. Malaria symptoms identified by local health workers were diarrhea, malnutrition, and upper respiratory infections (Temba 2013). A voluntary community health worker described her role in this area of high malaria transmission in this way, "I tell people to be clean and go to the hospital."

When available, this public government clinic gives away malaria drugs (mainly Artemether lumefantrine known locally as AL tablets) to those under 
5 years of age. One clinic employee is expected to provide community education about malaria transmission, symptoms, and treatment. When asked, What is taught about how the mosquito gets malaria, the nurse gave an incomplete answer. Clinics in this area do not cover their malaria patients with bed nets to prevent transmission to anopheline mosquitoes. This may be due to either a lack of resources, bed nets loaned to patients were not returned, or perhaps due to a lack of knowledge and understanding of the criticality of using bed nets. Bed nets are needed to prevent transmission of malaria from a critically ill person to an anopheline mosquito (Noboru and Ndjinga 2010). If female mosquitoes do not first get malaria, malaria cannot be passed to humans. If malaria is not passed to humans, human malaria will disappear from the area (Wiser 2010). Our observations and field data suggest that local malaria educators and those providing funding to this region do not understand how critical bed nets are to malaria prevention particularly preventing mosquitoes from taking blood with malaria protozoa from a person in the comatose stage of malaria.

\section{Desired quality of life and the resources for health}

For a community health intervention to be effective and sustainable, the first step is to understand the local situation and the community's desired quality of life (DQL). The most important things "to make life good" that were mentioned by the women interviewed, included: business, employment, profession, farming, and education of children (Table 3). Business and employment were the way cash resources were produced to sustain the DQL. Wealth among Luhya communities is reflected in television ownership and access to largely Western media. Farm income and off-farm employment provide food and clothing for families, as well as chlorine to sanitize drinking water, and cash for paying for elementary and secondary school tuition. Few jobs are available for men or women. For men or women there are school teacher or head teacher jobs. Men can become contractors, blacksmiths, store owners, bakers, farmers, or physicians (although no physician was found in the area during the study period and clinics appear to be run by nurses). Employment opportunities that are available to women include nurse, teacher, store owner, tailor, and hairdresser. As one study participant summarized,
"A job is most important. I have a son in college and cannot pay the school fees."

Women farmers in this high transmission, malaria epidemic area of Kenya depend on plentiful harvests to meet nutrition needs (see Footnotes 1, 3), and maintain health and quality of life. Plentiful harvests can also increase family resources for purchasing medicine and school fees (Table 3).

Based on our observations and field data, the quality of life could be improved by providing more options for protection against malaria. Education as well as sustainable and reusable and cost effective solutions are needed to further decrease malaria. Women's conversations about health centered on concerns over expenses related to non-reusable solutions such as mosquito repellent and malaria medication. Bed nets are reusable. For these women cost was a major factor inhibiting them from doing more to protect their family and themselves from malaria. Women explained: "Yes I use the bed net but I don't trust it because of the holes" and "I sleep under the bed net every night. I cannot use the net during the day." Many interviewees expressed frustration about these two issues, reporting that there were few easy and cheap ways to protect themselves during the day, and that the bed nets people owned were often very old, had holes, and would not work well. Bed nets were reported to be the primary method used to avoid malaria.

Preventing malaria transmission, not only the provision of medication and bed nets, in Kakamega County is key to reducing malaria deaths and ultimately to reducing rural, material poverty. Availability of medication is unreliable, often more expensive than what rural Kenyans can afford. As evident from our fieldwork, most women are unemployed and obtain cash through the sale of their corn. The typical selling price for corn in this area during the malaria season is $120 \mathrm{KSH}$ (about $\$ 1.30 \mathrm{USD}$ ) for a 90 kilogram bag, while a visit to a public health clinic in the largest town of Khwisero is $30 \mathrm{KSH}$ (\$0.30 USD). Malaria treatment at private health clinics, which are perceived as having better treatment than public clinics, is $500 \mathrm{KSH}$. Transportation costs to clinics would pose an additional economic burden.

To maintain health, women reported eating a balanced diet (see Footnotes 1, 3), eating adequately, living in a clean environment, and exercise (Table 4). Connections between food and health were noted by 
$52.5 \%$ of the respondents (Table 4). As one woman interviewed stated, "The most important aspects of quality of life are to be healthy and for the children to get an education and eat good food." For others, personal relaxation in a low stress life was paramount, as one respondent offered, "Eating ugali and drinking tea" were the most important factors for quality of life. HIV/AIDS and malaria were the most difficult health issues to avoid, women indicated (Table 5).

\section{Environmental factors}

Several environmental challenges emerge for malaria management in this part of Kenya, particularly near the Yala River. One is the nearness of communities to standing bodies of water, thereby creating habitat favorable for oviposition by anopheline mosquitoes whose larval populations should be monitored. Our observations indicated that there is no monitoring of population levels of larval or adult anopheline mosquitoes in Kakamega County. Brick-making processes for home-building also involve standing water pools. Second, the built environment renders the population at risk. And third, the region's tropical hydro-climatic regime influences patterns of human activity, and the behavior of mosquitoes that can carry malaria have adjusted their prime feeding periods to match the concentrated human economic and social activities of that particular geographic area.

First, the nearby Yala River flows during all seasons of the year so the River is not anopheline egg, larval, or pupa habitat; however, pools along river edges are stagnant and therefore attractive for female anopheline mosquitoes searching for favorable oviposition places. Anopheline mosquitoes require standing water for larval development. Standing water we observed is common throughout the district from near nightly rains during the rainy season. Bricks for building homes and community gathering structures are made from mud and clay at the river's edge but not in the river. This brick-making process creates new standing pools and when these pools become populated with bacteria and algae, an ideal habitat for rearing anopheline larvae is produced.

Second, nearly every house in the community has gaps between roofs and walls providing for easy entrance for mosquitoes (Fig. 2). Families generally eat the evening meal after sunset and inside with doors

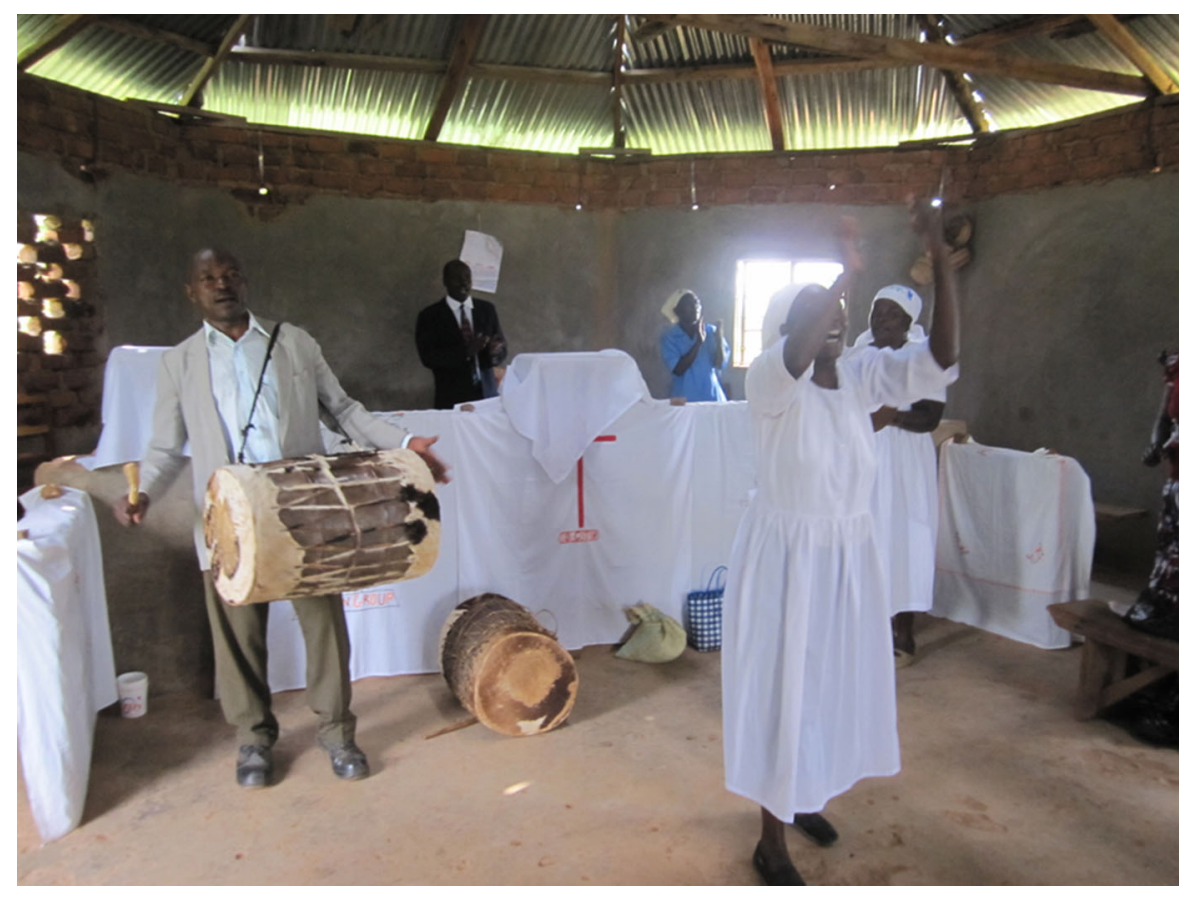

Fig. 2 Community structure in Eshinutsa illustrating the gap between the wall and the roof, perfect for entry of female anopheline mosquitoes seeking a blood meal from humans while delivering the protozoan causing malaria in humans (Photo Source: L. Hansen July 2013) 
and windows closed. However, there are few screen doors or windows; windows in wealthier households are covered with wood on hinges or glass.

Third, the region's tropical hydro-climatic regime influences patterns of human activity, and the behavior of mosquitoes that can carry malaria have adjusted their prime feeding periods to match the concentrated human economic and social activities of that particular geographic area. The typical daily pattern is breakfast is served inside before sunrise and as the intense daytime heat subsides in the evening, family members gather, meals are served inside, and storytelling begins. Inactive under a bed net at breakfast time is considered lazy and in the early evening is considered anti-social. Anopheline mosquitoes vectoring malariacausing protozoa are evolving a variety of indoor and outdoor behavior patterns to meet changes in human behaviors. Peak biting times for anopheline mosquitoes are dawn, several hours before dusk, and several hours after (Yohannes and Boelee 2012; Harris et al. 2006), coinciding with peak times of social interactions and livelihood activities. Reports of Anopheles gambiae and Anopheles funestus in Uganda, however, indicate 11:00 pm to 5:00 am are peak biting times (Kabbale et al. 2013). In other areas of Sub-Saharan Africa, peak biting time shifts with the nature of the intervention (Reddy et al. 2011). Not only are insecticide-treated nets (ITNs) expensive, but in the social system combined with the $12 \mathrm{~h}$ cycle of light to dark in this part of equatorial Africa, bed nets are not effective during peak vector biting times. Bed nets are designed to prevent transmission of malaria-causing protozoa by female anopheline mosquitoes. Transmission could be from mosquitoes to a healthy human or to mosquitoes from comatose humans in the fever stage of malaria when gametocytes of malaria-causing protozoa are in peripheral circulatory systems, accessible to mosquito (Wiser 2010).

Opportunities for bio-cycle storytelling and other forms of place-based malaria prevention techniques

In the Eshinutsa area we found both community involvement in vector management and knowledge of bio-cycles was limited. Stories in Luhya could broadly spread this information among the Luhya people. When we learned that parts, but not the entire biocycle stories of the protozoan and the mosquito were known by the women, we shared these stories through an informal story telling process with them after all indepth interviews were completed (Fig. 3). This informal storytelling took place in the Eshinutsa Health Center with study participants and the Center personnel. The intertwined bio-cycles were drawn in situ by a member of our research team while she told the story and the translators described it in Luhya (Figs. 4, 5).

Bio-cycle stories create awareness and successful knowledge transfer if the information in them is biologically correct. Schools in Western Kenya have been recognized as the main avenue for information dispersal and are likely to be useful in health education (Musuva et al. 2014) as were village schools in rural Mali (Dunkel et al. 2013; Dunkel and Giusti 2012; Dunkel et al. 2011). A high knowledge base of the entire community leads to sustained implementation of environmental management by the community. This was suggested by Okech et al. (2008) as having played a central role in reducing mosquito populations and malaria transmission in central Kenya (Mutero et al. 2004, Kibe et al. 2006). Our results show that malaria bio-cycle information provided in the local school system may be incomplete.

Luhya culture is orally-based; important information is transferred in stories, generally from elders to younger generations. This cultural component can be a strong tool for eliminating malaria. Listening is a vital skill in indigenous education, allowing people to come to consensus in decision making which is mandatory for a peaceful co-existence (Khasandi-Telewa et al. 2012). Children are taught to wait without interruption for the ending of stories and learn to internalize lessons while being entertained. Luhya children are also taught oratory skills starting from an early age, including how to tell a story. Grandparents have many opportunities to share stories with local children who are taught to respect their elders. Community involvement is an important component of the National Malaria Control Strategy in Kenya and numerous volunteer community groups have arisen in coastal urban areas; nevertheless, in-depth study of these groups, Kibe et al. (2006) found more education was needed on malaria, vectors and their habitats.

Interview data and observations further suggested that women possess knowledge about the use of local medicinal plants and identify other opportunities for the community to move toward the local elimination 


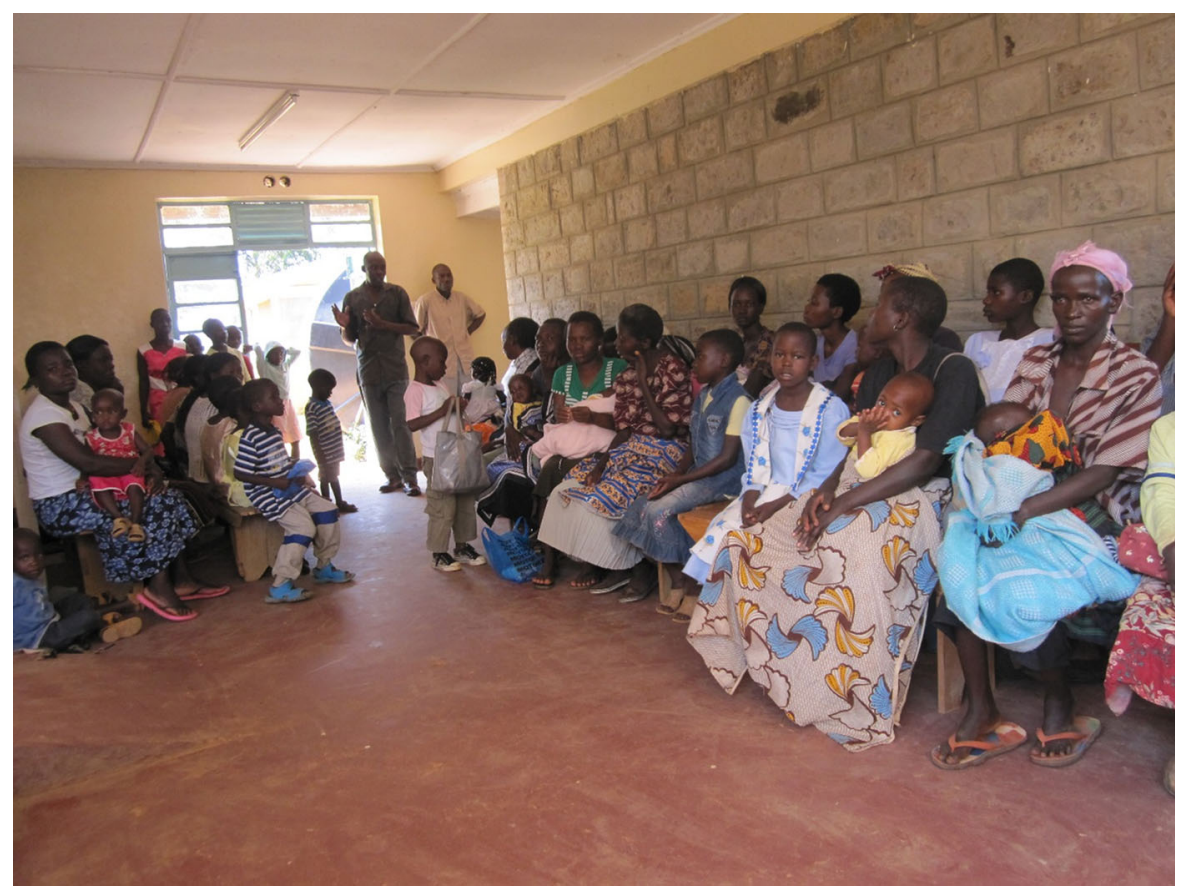

Fig. 3 Women participants at the Eshinutsa Health Center listening to the bio-cycle stories of the mosquito carrying the protozoan that causes malaria and the protozoan itself in the local language Luhya (Photo Source: L. Hansen, July 2013)

Fig. 4 Example of participatory diagram created (hand-drawn) while telling the mosquito biocycle story for women after their interview in the informal meeting groups in Khwisero District or in the Health Center (source: Dunkel 2015)

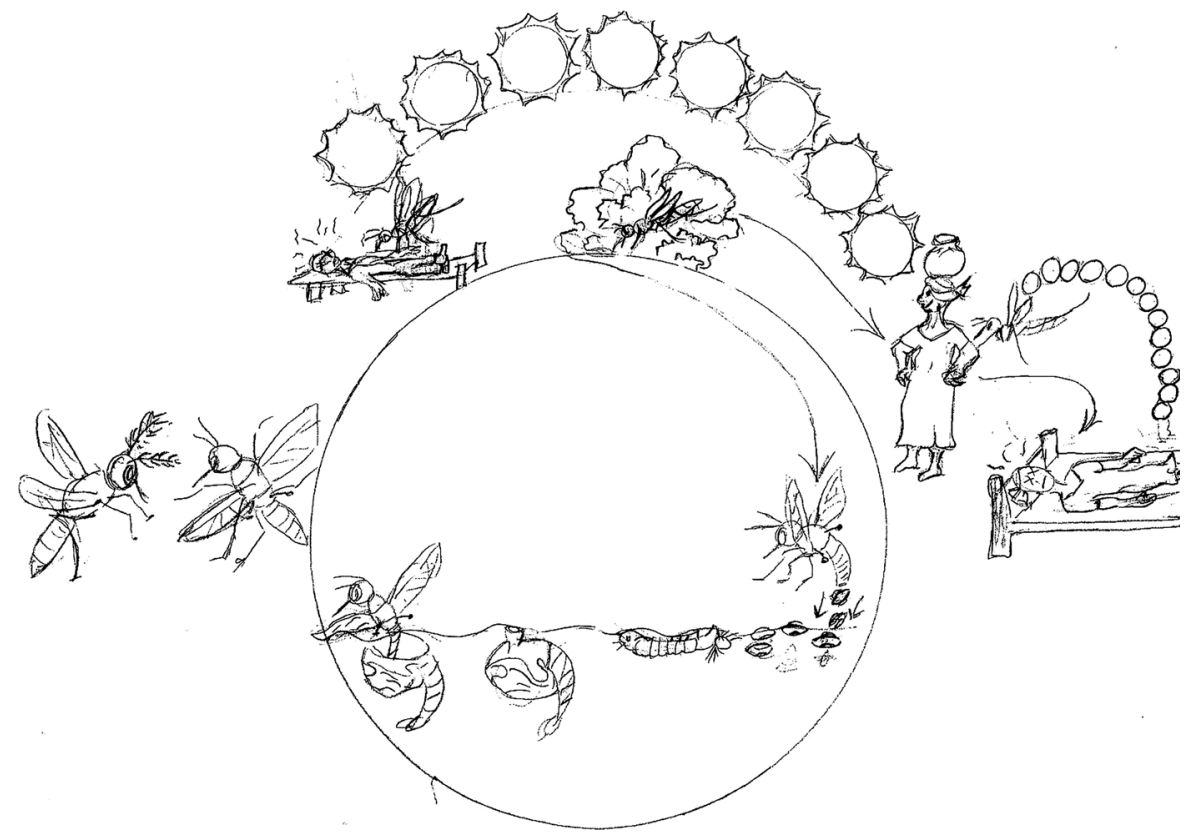

of malaria. For example, commercial repellent lotions would be difficult to distribute in Kakamega County because residents consider them too expensive. Interestingly, the neem tree, Azadirachta indica which grows in this area, is an insect growth regulator (prevents adult development) for anopheline mosquitoes (Luong et al. 2012) and is a repellent for adult mosquitoes (Dunkel 2015). Using neem leaf slurry as a repellent dip for cloths, clothes, or even bed nets or in homemade soap are potential local solutions that do 
Fig. 5 Example of the participatory diagram handdrawn for women after their interview during the telling of the bio-cycle story of the protozoan that causes human chronic malaria with days represented by sun images (circles) (source: Dunkel 2015)

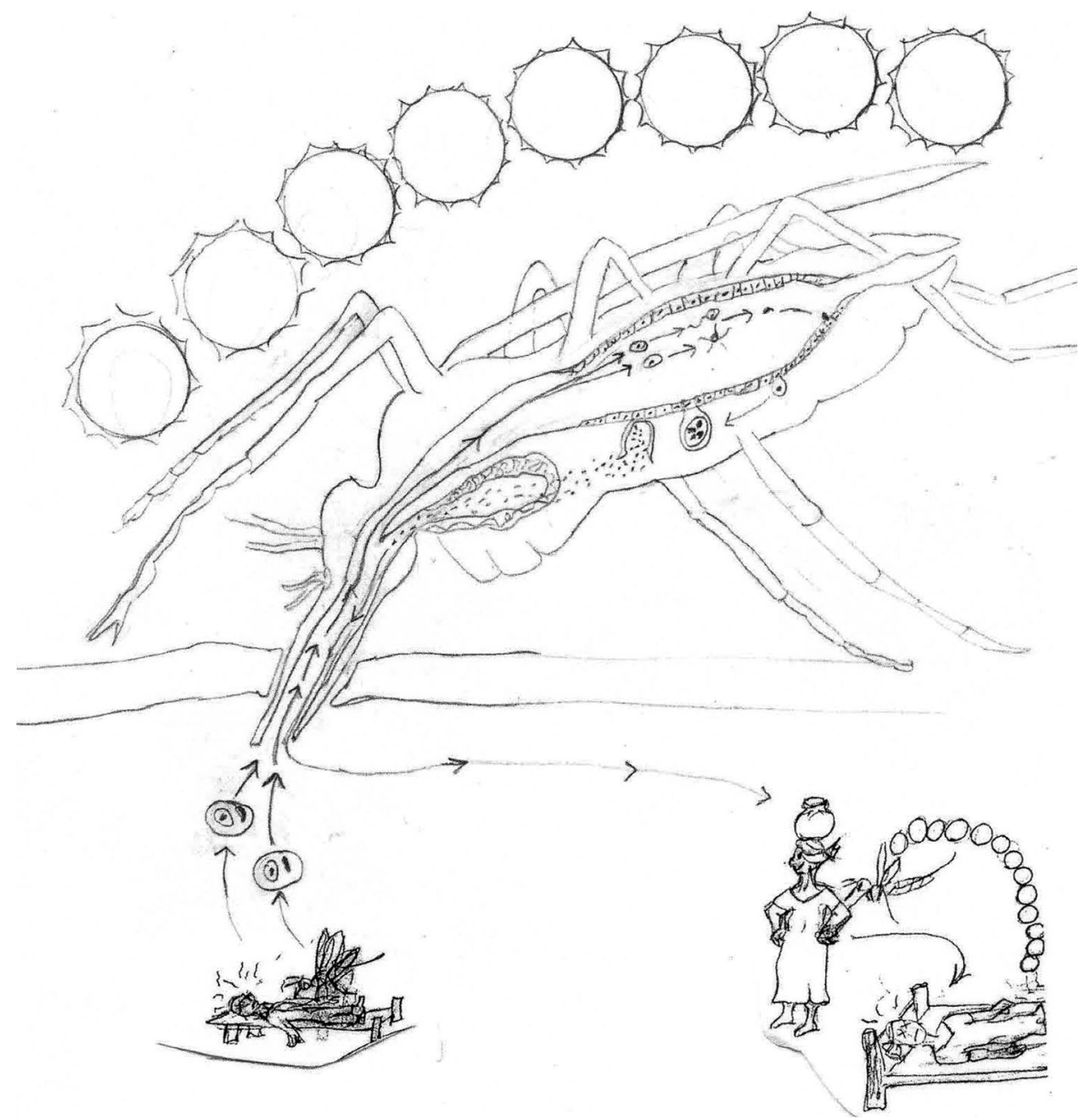

not require cash in this region of Kenya. Another example of local environmental positives the women of Khwisero can implement is to monitor the standing pools of water for anopheline mosquito larvae and either get rid of the water or treat the water with neem leaf slurry. Women can make architectural and construction improvements to homes and community gathering halls for mosquito exclusion by using the by-products of corn harvesting such as corn husks. Field observations indicated feral and cultivated Artemisia annua, known to naturally repel mosquitoes, is available in Kakamega County. Only 4 of the 60 women interviewed knew of A. апnиa and only four used tablets containing artemisinin. Only one of the 60 women used artemisinin tablets as a malaria preventative. Experiments with slurries of fresh plants showed in vitro and in vivo activity 6-18 fold better than pure artemisinin alone (Wright et al. 2010). Hot tea from whole plants seems most efficacious with over 600 metabolites identified, all of which might play a role in synergism and greatly postpone drug resistance in malaria-causing protozoa (Van der Kooy and Sullivan 2013; Van der Kooy and Verpoorte 2011). A. апnиa infusions and decoctions have been used for centuries without resistance. Resistance only develops when one of these hundreds of active components such as artemisinin is isolated and used as a mono-therapy (Van der Kooy and Sullivan 2013). These environmental opportunities are local solutions that only require knowledge, rather than cash to implement.

\section{Concluding remarks and recommendations}

Malaria incidence in Kakamega County demonstrates a complex interplay of social and ecological processes contributing to disease vulnerability. Indeed, telling 
insights into the local complexities are conveyed in Thurow's (2012) work that centers on the crippling hunger season that coincides with the malaria season in this part of Kenya.

Our study underscores several key points. First, although malaria affects over $90 \%$ of families in this part of western Kenya and women interviewed considered malaria one of the two most difficult health issues to manage, we did not find it mentioned as a main factor interfering with the women's quality of life. Paralleling the findings of Thurow (2012), food and education were reported as the two most desired qualities of life. The focus is on generating cash incomes from farming or off-farm activities to meet nutritional needs and provide for education. The impact of malaria on childhood survival and on adults' abilities to support families was not considered a source of worry. Our observations suggest that malaria is widely viewed as an inevitable fact of life that saps energy and threatens lives.

Second, the linkages between resilience to malaria and sufficient nutritional inputs for children were not consciously recognized. Stunting, both cognitive and physical stunting, is widespread in this area; more than two hundred out of 1000 children born annually in Kakamega County die due to the under-nutrition of their mothers (Kabaka 2013). Corn continues to be the most important crop, yet harvests are curtailed by the parasitic weed striga (Sands et al. 2015). While the main corn-based foodstuff, ugali, is preferred by the Luhya people, it lacks strong dietary components that would supply the amino acids, lysine and tryptophan, that are currently missing from the diet. This form of under-nutrition renders the population less able to resist and overcome infectious diseases such as malaria (Friedman et al. 2005). It may be necessary to supply nutritional support and dietary information in addition to malaria treatment, an approach adopted for HIV/AIDS patients as well as in other health intervention contexts in Kenya (Nagata et al. 2014; UNICEF 2013).

A third observation is that the health infrastructure at community and household scales is neglected, in part, because Kakamega County is on the periphery in a marginalized border zone that is far from Nairobi and major coastal tourist destinations. Access to clean water and latrines is limited despite some improvements in public areas such as schools. The particularities of the built environment also contribute to the disease ecology. Home construction allows for gaps between outer walls and roofs to aid airflow; these gaps problematically allow anopheline mosquitoes to enter homes to obtain blood meals, which is the only way to pass the malaria-causing protozoan from person to person. Since people are the only reservoir of the five human-host malaria species, blocking access to those infected, especially in the fever stage, will over time result in the local elimination of the protozoan.

Another observation concerns the understanding and communication of the story of malaria's bio-cycle. We found that only 50-66 \% of the women understood the fundamental part of the malaria bio-cycle story and much more attention could emphasize indigenous oral tradition to convey vital malaria-related information. Nevertheless, questions emerge: Has storytelling among the Luhya people declined in concert with Westernization? Could social, economic, and ecological factors pertaining to malaria transmission be sustained through the Luhya oral tradition? A potential future avenue for inquiry would be to investigate the storytelling tradition and the viability of using storytelling for health communication.

The elimination of malaria in Kakamega County would require at least four factors to come together simultaneously. These factors are: (1) recognition by the women in this area that chronic malaria and their children's death from malaria is not a necessary fact of life; (2) understanding of the intertwined bio-cycles of the anopheline mosquitoes and the malaria-causing protozoa by all genders and ages of people in the community; (3) understanding how to break both of these bio-cycles such as by revising the house structure to eliminate the gap between the walls and the roof; and (4) reconnecting to traditional ecological knowledge that contained information about local plants that have strong mosquito repellent properties and can be used as clothes treatments or other plants that can be used against the malaria-causing protozoan itself. At the macro-level, creative cottage industries that provide ready cash for women particularly during the coinciding hunger and malaria seasons will have a great influence on health and well-being (Dunkel et al. 2013). Women-led, village-based, cottage industries and a microloan system have been successful in similar rural, malaria-endemic areas of southern Mali (Dunkel et al. 2013) and are suggested approaches in eastern Kenya (Kibe et al. 2006). If these cottage 
industries that increase cash in the hands of women could also supply missing nutrients, such as, essential amino acids missing in corn but found in local food insects (Footnote 1) that could be sold as snacks or insects for chicken feed, issues contributing to material poverty, including malaria, could be eliminated. This wider structural factor may also drive changes in the micro-level factors mentioned above.

These findings suggest that in remote and marginalized communities a whole view of life is required to understand the interplay of health and place. This examination requires beginning with the holistic process to determine the underlying, fundamental view of quality of life (Savory and Butterfield 1999, Dunkel et al. 2013) and what the community, particularly the women, perceive are the resources and forms of production of these resources that they can use to create this quality. Further research that highlights the connections between quality of life, resources, and forms of production of these resources will help in application of these findings. Finally, as suggested by Bisung et al. (2015), Dennis et al. (2009), and Chambers et al. (1989), photovoice, other participatory photography methods, and simply participatory, hand-drawn diagrams with storytelling should be used for direct interventions. This project is the opening process in that form of a health intervention focused on a holistic vision of the desired quality of life of those at risk to malaria.

Acknowledgments The authors wish to thank local residents of Kakamega County for their time and willingness to participate in this study. Much gratitude goes to Margaret Ayiti and Jared Okaalo for their translation services. This study was funded by the Montana State University (MSU) Undergraduate Scholar's Program, the MSU Office of the President as part of the 2013 Teaching Excellence Award, and the Montana Agricultural Experiment Station. This study was made logistically possible by the MSU chapter of Engineers Without Borders. The insightful comments and careful reviews from: Matthew Smith, School of International and Public Affairs, Columbia University, New York City, New York; Ronald Omyonga, Nairobi, Kenya originally from Kakamega Co, Kenya; and the GeoJournal reviewers are greatly appreciated.

\section{Compliance with ethical standards}

Ethical standards Institutional Review Board at Montana State University approved an exemption-from-review May 16, 2013 to conduct interviews with human subjects. Women interviewed were asked for their informed consent, signed waivers indicating such, or gave verbal consent recorded on tape if they were not able to sign their name. If the women could not read English, waivers were explained by translators in the women's native tribal language, Luhya.

Open Access This article is distributed under the terms of the Creative Commons Attribution 4.0 International License (http:// creativecommons.org/licenses/by/4.0/), which permits unrestricted use, distribution, and reproduction in any medium, provided you give appropriate credit to the original author(s) and the source, provide a link to the Creative Commons license, and indicate if changes were made.

\section{References}

Abubakar, A., Van Baar, A., Fischer, R., Bomu, G., \& Gona, J. (2013). Socio-cultural determinants of health-seeking behaviour on the Kenyan coast: A qualitative study. PLoS One. doi:10.1371/journal.pone.0071998.

Atuti Atera, E., Ishii, T., Onyango, J.C., Itoh, K. and Azuma, T. (2013). Striga infestation in Kenya: Status, distribution and management options. Sustainable Agriculture Research, 2(2), 99-108. http://www.ccsenet.org/journal/index.php/ sar/article/view/20838.

Bisung, E., Elliott, S., Abudho, B., Karanja, D., \& SchusterWallace, C. (2015). Using photovoice as a community based participatory research tool for changing water, sanitation, and hygiene behaviours in Usoma, Kenya. BioMed Research International. doi:10.1155/2015/903025.

CDC. (2015). Malaria. Atlanta: Centers for Disease Control and Prevention webpage. http://www.cdc.gov/malaria/. Accessed 27 Sept 2015.

Chambers, R., Pacey, A., \& Thrupp, L. (Eds.). (1989). Farmer first: Farmer innovation and agricultural research. New York: Bootstrap Press.

Dennis, S., Gaulocher, S., Carpiano, R., \& Brown, D. (2009). Participatory photo mapping (PPM): Exploring an integrated method for health and place research with young people. Health and Place, 15(2), 466-473.

Deribew A., F. Alemseged, F. Tessema, L. Sena, Z. Birhanu, \& A. Zeynudin et al. (2010). Malaria and under- nutrition: A community based study among under-five children at risk of malaria, South West Ethiopia. PLoS One, 5(5). doi:10. 1371/journal.pone.0010775.

Doannio, J., Konan, Y., Amalaman, K., Attiah, J. (2004). Knowledge, attitudes and practices of populations towards mosquitoes in urban and rural area (Côte D'Ivoire-West Africa). Bulletin De La Societe De Pathologie Exotique. Accessed 19 June 2014. https://www.researchgate.net/ publication/6500291_Knowledge_attitudes_and_practices_ of_populationtowards_mosquitoes_in_urban_and_rural_ area_Cote_d\%27Ivoire_-_West_Africa.

Dunkel, F. (2015). Bio-based mosquito repellents. Unpublished field data. Bozeman, MT: Montana State University.

Dunkel, F., Coulibaly, K., Montagne, C., Luong, K., Giusti, A., \& Coulibaly, H. et al. (2013). Sustainable integrated malaria management by villagers in collaboration with a transformed classroom using the holistic process: Sanambele, Mali, and Montana State University, U.S.A. American Entomologist, 59(2), 15-24. http://ae.oxfordjournals.org/ content/59/1/45. 
Dunkel, F., \& Giusti, A. (2012). French students collaborate with Malian villagers in their fight against malaria. In J. Thomas (Ed.), Etudiants Sans Frontières (Students without borders): Concepts and models for service-learning in French (pp. 135-150). Washington, DC: American Association of Teachers of French.

Dunkel, F., Shams, A., George, C. (2011). Expansive collaboration: A model for transformed classrooms, communitybased research, and service-learning. North American College Teachers of Agriculture Journal, 55(Dec), 65-74. http://www.montana.edu/mali/pdfs/ExpansiveCollaborati onDec2011NACTAJournal.pdf.

Ehrhardt, S., Burchard, G., Mantel, C., Cramer, J., Kaiser, S., Kubo, M., et al. (2006). Malaria, Anemia, and Malnutrition in African Children- Defining Intervention Priorities. The Journal of Infectious Disease, 194(1), 108-114.

Engineers Without Borders. (2015). Composting latrines workshop at Eshinutsa Elementary School. Montana State University. https://www.facebook.com/media/set/?set=a.98 4930531541354.1073741831.210384082329340\& type $=3$. Accessed 28 Sept 2015.

FAO. (1992). Maize in human nutrition. FAO Food and Nutrition series no. 25. Rome, Italy: Food and Agricultural Organization of the United Nations.

Feachem, R. (2009). The Malaria Elimination Group. Shrinking the malaria map: A guide on malaria elimination for policy makers. San Francisco, California: The Global Health Group, Global Health Sciences, University of California, San Francisco. http://www.malariaeliminationgroup.org/ sites/default/files/fileuploads/AGuideonMalariaEliminati onforPolicyMakers.pdf. Accessed 28 Sept 2015.

Ferreira, E., Alexandre, M., Salinas, J., de Siqueira, A., Benzecry, S., \& de Lacerda, M. et al. (2015). Association between anthropometry-based nutritional status and malaria: A systematic review of observational studies. Malaria Journal, 14, 346. doi:10.1186/s12936-015-0870-5.

Friedman, J., Kwena, A., Mirel, L., Kariuki, S., Terlouw, D., Phillips-Howard, P., et al. (2005). Malaria and nutritional status among pre-school children: Results from cross-sectional surveys in western Kenya. American Journal of Tropical Medicine Hygiene, 73(4), 698-704.

Gatton, M., Chitnis, N., Churcher, T., Donnelly, M., Ghani, A., Godfray, H., et al. (2013). The importance of mosquito behavioral adaptations to malaria control in Africa. Evolution, 67, 1218-1230.

Gitonga, C., Karanja, P., Kihara, J., Mwanje, M., Juma, E., Snow, R., et al. (2010). Implementing school malaria surveys in Kenya: Towards a national surveillance system. Malaria Journal, 9, 306. doi:10.1186/1475-2875-9-306.

Glinz, D., Hurrell, R. F., Ouattara, M., Zimmermann, M., Brittenham, G., Adiossan, L., et al. (2015). The effect of ironfortified complementary food and intermittent preventive treatment of malaria on anaemia in 12- to 36- month-old children: A cluster-randomized controlled trial. Malarial Journal, 14, 347. doi:10.1186/s12936-015-0872-3.

Glinz, D., Kamiyango, M., Phiri, K., Munthall, F., Zeder, C., Zimmermann, M., et al. (2014). The effect of timing of iron supplementation on iron absorption and haemoglobin in post-malaria anaemia: A longitudinal stable isotope study in Malawian toddlers. Malaria Journal, 13, 397. doi:10. 1186/1475-2875-13-397.
Halvorson, S. (2003). 'Placing' health risks in the Karokoram: Local perceptions of disese, dependency, and social change in northern Pakistan. Mountain Research and Development, 23(3), 271-277.

Halvorson, S. (2004). Women's management of the household health environment: Responding to childhood diarrhea in the Northern Areas, Pakistan. Health and Place, 10(1), 43-58.

Halvorson, S., Williams, A., Ba, S., \& Dunkel, F. (2011). Water Quality and Waterborne Disease in the Niger River Inland Delta, Mali: A Study of Local Knowledge and Response. Health and Place, 17(2), 449-457.

Harris, A., Matias-Arnez, A., \& Hill, N. (2006). Biting time of Anopheles darlingi in the Bolivian Amazon and implications for control of malaria. Transactions of the Royal Society of Tropical Medicine and Hygiene, 100(1), 45-47.

IBM Corp. (2013). IBM SPSS Statistics for Windows. Version 22.0. Armonk: IBM Corp. New York.

Kabaka, J. (2013). Sh. 1.35 billion for fighting malnutrition in Kakamega County. West FM times. http://westfm.co.ke/ index-page-news-bid-9604.htm\#ixzz3hUfT3QV3. Accessed 28 Sept 2015.

Kabbale, F., Akol, A., Kaddu, J., \& Onapa, A. (2013). Biting patterns and seasonality of Anopheles gambiae sensu lato and Anopheles funestus mosquitoes in Kamuli District. Uganda: Parasites and Vectors. doi:10.1186/1756-3305-6340 .

Khan, Z., Pickett, J., Wadhams, L., Hassanali, A., \& Midega, C. (2006). Combined control of Striga hermonthica and stemborers by maize-Desmodium pp. Intercrops. Crop Protection, 25(9), 989-995.

Khasandi-Telewa, V., Liguyani, R.I., Wandera-Simwa, S. (2012). Appropriating globalization to revitalize indigenous knowledge and identity through Luhya children's play songs. Journal of Pan African Studies, 5(6), 17. http:// connection.ebscohost.com/c/articles/83046448/appropriat ing-globalisation-revitalise-indigenous-knowledge-identitythrough-luhya-childrens-play-songs.

Kibe, L., Mbogo, C., Keating, J., Molyneux, S., Githure, J., \& Beier, J. (2006). Community based vector control in Malindi, Kenya. African Health Sciences, 6(4), 240-246.

KNBS. (2009). Kenya 2009 population and health statistics. Kenya National Bureau of Statistics. http://www. knbs.or.ke/index.php?option=com_phocadownload\&view =category\&id+73\&Itemid=1131. Accessed 1 Apr 2015.

KNBS. (2012). Outpatient morbidity in patients 5 years of age in 2012, by County. Nairobi: Kenya National Bureau of Statistics. https://data.hdx.rwlabs.org/dataset/countyoutpatient-morbidity-for-patients-below-5-years-of-age-in2013/resource/af196946-85ea-483e-8a1f-e34e8a538947. Accessed 28 Sept 2015.

Looy, H., Dunkel, F. V., \& Wood, J. R. (2013). How then shall we eat? Insect-eating attitudes and sustainable foodways. Agriculture and Human Values, 31(1), 131-141. doi:10. 1007/s10460-013-9450-x.

Luong, K., Dunkel, F., Coulibaly, K., \& Beckage, N. (2012). Use of neem (Azadirachta indica A. Juss.) leaf slurry as a sustainable dry season management strategy to control the malaria vector Anopheles gambiae Giles s.s. (Diptera: Culicidae) in West African villages. Journal of Medical Entomology, 49(6), 1361-1369. doi:10.1603/ME12075. 
Maketa, V., Mavoko, H. M., Inocencio da Luz, R., Zanga, J., Lubiba, J., Kalonji, A., et al. (2015). The relationship between Plasmodium infection, anaemia and nutritional status in asymptomatic children aged under five years living in stable transmission zones in Kinshasa, Democratic Republic of Congo. Malaria Journal, 14, 83. doi:10.1186/ s12936-015-0595-5.

Matthys, B., N'Goran, E., Koné, M., Koudou, B., Vounatsou, P., Cissé, G., et al. (2006). Urban agricultural land use and characterization of mosquito larval habitats in a mediumsized town of Côte d'Ivoire. Journal of Vector Ecology, 31(2), 319-333.

Mbug, E., Meijerink, M., Veenemans, J., Jeurink, P., McCall, M., Olomi, R., et al. (2010). Alterations in early cytokinemediated immune response to Plasmodium falciparum infection in Tanzanian children with mineral element deficiencies: A cross-sectional survey. Malaria Journal, 9, 130. doi:10.1186/1475-2875-9-130.

MCH/WHO. (2014). Kenya: Neonatal and child health profile. http://www.who.int/pmnch/media/membernews/2011/ 20121216_kenyaparliament.pdf. Accessed 28 Sept 2015.

MMV. (2015). Medicines for malaria venture. http://www. mmv.org/malaria-medicines/five-species. Accessed 28 Sept 2015.

Murray, C., \& Bennett, J. (2009). Rapid diagnosis of malaria. Interdisciplinary Perspectives on Infectious Diseases. doi:10.1155/2009/415953.

Musuva, R., Awiti, A., Omedo, M., Ogutu, M., Secor, W., Motgomery, S., Alaii, J., Mwinzi, P. (2014). Community knowledge, attitudes and practices on schistosomiasis in Western Kenya-The SCORE Project. The American Journal of Tropical Medicine and Hygiene, 90(4), 646-652. doi:10.4269/ajtmh.13-0488. Accessed 29 Mar 2014.

Mutero, C., Kabutha, C., Kimani, V., Kabuage, L., Gitau, G., Ssennyonga, J., et al. (2004). A transdisciplinary perspective on the links between malaria and agroecosystems in Kenya. Acta Tropica, 89(2), 171-186.

Nagata, J., Cohen, C., Young, S., Wamuyu, C., Armes, M., Otieno, B., Leslie, H., Dandu, M., Stewart, C., Bukusi, E., Weiser, S. (2014). Descriptive characteristics and health outcomes of the food by prescription nutrition supplementation program for adults living with HIV in Nyanza Province, Kenya. PLoS One, 9(3), e91403. doi:10.1371/ journal.pone.0091403.

Noboru, M., \& Ndjinga, J. (2010). The importance of education to increase the use of bed nets in villages outside of Kinshasa, Democratic Republic of the Congo. Malaria Journal, 9, 279. doi:10.1186/1475-2875-9-279.

Okech, B., Mwobobia, I., Kamau, A., Muiruri, S., Mutiso, N., Nyambura, J., et al. (2008). Use of integrated malaria management reduces malaria in Kenya. PLoS One, 3(12), e4050.

Omole, O., Adenuga, B., Adeoye, J. (2015). Opinion: The new vaccine that could mean the end of malaria. Market Watch. http://www.marketwatch.com/story/the-new-vaccine-thatcould-mean-the-end-of-malaria-2015-09-10?siteid=rss\& rss=1. Accessed 14 Sept 2015.

Omyonga, R. (2014). Member of the Luhya nation from the Khwisero District. Professional architect, Nairobi, Kenya, initiated the Khwisero District EWB-MSU project. Personal Communication.
Oswald, A. (2005). Striga control-Technologies and their dissemination. Crop Protection, 24(4), 333-342.

Parker, G. (1952). British policy and native agriculture in Kenya and Uganda. Agricultural History, 26, 125-131. http:// kenyadb.freeservers.com/index1.htm. http://www.amazon .com/BRITISH-POLICY-NATIVE-AGRICULTURE-UG ANDA/dp/B00KJ1PNAC/ref=sr_1_fkmr0_1?ie=UTF8 \&qid $=1453159119 \& \mathrm{sr}=8-1-\mathrm{fkmr0} \&$ keywords $=41 .+$ Park er\%2C+G.+\%281952\%29.+British+Policy+and+Nati $\mathrm{ve}+$ Agriculture + in + Kenya + and + Uganda. + Agricultural + History. $+26 \% 2 \mathrm{C}+125-131$.

Reddy, M., Overgaard, H., Abaga, S., Reddy, V., Caccone, A., \& Kiszewski, A., et al. (2011). Outdoor host seeking behaviour of Anopheles gambiae mosquitoes following initiation of malaria vector control on Bioko Island, Equatorial Guinea. Malaria Journal, 10, 184. doi:10.1186/ 1475-2875-10-184.

Roless Media and Management Institute (RMMI). (2010). Establishment of Khwisero development initiative (DIProject) baseline survey report. Report Dec. 2010. for ActionAid International Kenya by RMMI, PO 14240-00100, Nairobi, Kenya. Print.

Sands, D., Pilgeram, A., Morris, C., Oyosi, F., Nzioki, S., Baker, C. (2015). Biocontrol of striga at the village level to save labor and increase food security. Phase I Financial and Scientific Report. Bill and Melinda Gates Foundation. Montana State University, Dept. Plant Sciences and Plant Pathology.

Savory, A., \& Butterfield, J. (1999). Holistic management: A new framework for decision making. Washington, DC: Island Press.

Sharma, V. P. (2009). Hidden burden of malaria in Indian women. Malaria Journal, 8, 281-285. doi:10.1186/1475-2875-8281. http://www.malariajournal.com/content/8/1/281.

Singh, N., Awadha, S. B., Dash, A. P., \& Shrivastava, R. (2005). Malaria during pregnancy: A priority area for malaria research and control in South East Asia. Regional Health Forum, 9(1), 7-18.

Singh, B., \& Daneshvar, C. (2013). Human infections and detection of Plasmodium knowlesi. Clinical Microbiology Reviews, 26(2), 165-184. doi:10.1128/CMR.00079-12.

Smith, D. L., Cohen, J. M., Moonen, B., Tatem, A. J., Sabot, O. J., \& Ali, A., et al. (2011). Solving the Sisyphean problem of malaria in Zanzibar. Science, 332(6036), 1384-1385.

Temba, R. (2013). Nurse in charge of the Eschinutsa Health Center, Khwisero District. Personal communication: Kenya.

Thurow, R. (2012). The last hunger season: A year in an African farm community on the brink of change. New York: Public Affairs, Perseus Book Group.

Tusting, L., Willey, B., Lucas, H., Thompson, J., Kafy, H., \& Smith, R., et al. (2013). Socioeconomic Development as an Intervention against Malaria: A Systematic Review and Meta-analysis. The Lancet, 382(9896), 963-972.

UNICEF. (2013). Kenya statistical report. http://www.unicef. org/infobycountry/kenya_statistics.html. Accessed $27 \mathrm{Sept}$ 2015.

Van der Kooy, F., \& Sullivan, S. (2013). The complexity of medicinal plants: The traditional Artemisia annua formulations, current status and future perspectives. Journal of Ethnopharmacology, 150(1), 1-13. 
Van der Kooy, F., \& Verpoorte, R. (2011). The content of artemisinin in the Artemisia annua tea infusion. Planta Medicine, 77(15), 1754-1756. doi:10.1055/s-00301271065.

van Huis, A., Itterbeeck, J. V., Klunder, H., Mertens, E., Halloran, A., \& Muir, G., et al. (2013). Food and Agriculture Organization of the United Nations. Edible Insects: Future Prospects for Food and Feed Security, Food and Agriculture Organization of the United Nations, Forestry Report \#171. Rome, Italy.

Watt, W. (1936). Control of striga weed in Nyanza Province, Kenya. East African Agricultural Journal, 1(4), 320-322. http://www.tandfonline.com/doi/abs/10.1080/03670074. 1936.11663677.

WHO. (2014a). Children: Reducing mortality. WHO Fact Sheet No. 178. http://www.who.int/mediacentre/factsheets/ fs178/en/. Accessed 27 Sept 2015.

WHO. (2014b). World malaria report. http://www.whoint/ malaria/publications/world_malaria_report_2014/wmr2014-no-profiles.pdf. Accessed 26 Aug 2015.

WHO. (2014c). Malaria. World Health Organization Report. http://www.afro.who.int/en/clusters-a-programmes/dpc/ malaria/features/2287-10-facts-on-malaria-in-africa.html. Accessed. 26 Aug 2014.

Wiser, M. (2010). Protozoa and human disease. Garland Science. http://www.tulane.edu/ wiser/protozoology/notes/ malaria.html\#cycle. Accessed 28 Sept 2015.

Woodward, J. (2014). Indigenous diets fight modern illnesses. The Guardian. http://www.theguardian.com/globaldevelopment/2014/feb/03/indigenous-diets-fight-modernillnesses. Accessed 28 Sept 2015.

United Nations Inter-agency Group for Child Mortality Estimation (UN IGCME). (2014). Levels and Trends in Child Mortality: Report 2014. New York: United Nation's Children's Fund. http://www.unicef.org/media/files/ Levels_and_Trends_in_Child_Mortality_2014(1).pdf.

Wright, C., Linley, P., Brun, R., Wittlin, S., \& Hsu, E. (2010). Ancient Chinese methods are remarkably effective for the preparation of artemisinin-rich extracts of Qing Hao with potent antimalarial activity. Molecules, 15(2), 804-812.

Yohannes, M., \& Boelee, E. (2012). Early biting rhythm in the Afro-tropical vector of malaria, Anopheles arabiensis, and challenges for its control in Ethiopia. Medical and Veterinary Entomology, 26(1), 103-105. 